\title{
28 Research Square

\section{Surface bio-interactions stand at the base of the short-term nano CuO-induced cell oxidative stress: insights for a safe(r)-by-design approach}

Paride Mantecca ( $\square$ paride.mantecca@unimib.it)

University of Milano Bicocca

Elisa Moschini

University of Milano Bicocca

Graziano Colombo

Università degli Studi di Milano

Giuseppe Chirico

University of Milano Bicocca

Giancarlo Capitani

University of Milano Bicocca

Isabella Dalle-Donne

Università degli Studi di Milano

\section{Article}

Keywords: Copper oxide nanoparticles, oxidative stress, protein oxidation, apoptosis, surface defects, cellparticle interaction, safe(r)-by-design

Posted Date: April 28th, 2022

DOI: https://doi.org/10.21203/rs.3.rs-1306935/v2

License: (c) (1) This work is licensed under a Creative Commons Attribution 4.0 International License.

Read Full License 


\section{Abstract}

\section{Background:}

It is well known that copper oxide nanoparticles (CuO NPs) are heavily toxic on in vitro systems. In human alveolar epithelial cells, the mechanism of toxicity is mostly related to oxidative insults, coming from intracellularly dissolved copper ions, finally leading to apoptotic or autophagic cell death.

Our hypothesis is based on possible early oxidative events coming from specific NP surface reactivity able to undermine the cell integrity and to drive cell to death, independently from lysosomal-enhanced Trojan horse mechanism.

Two types of CuO NPs, with different oxidative potential, were selected and tested on A549 cells for $1 \mathrm{~h}$ and $3 \mathrm{~h}$ at $10,25,50$ and $100 \mathrm{mg} / \mathrm{mL}$. Cells were then analyzed for viability and oxidative change of the proteome. Oxidative by-products were localized by immunocytochemistry and cell-NP interactions characterized by confocal and electron microscopy techniques.

\section{Results:}

CuO NPs induced oxidative changes soon after $1 \mathrm{~h}$ exposure as revealed by the increase in protein carbonylation and reduced-protein-thiol oxidation. In parallel, cell viability significantly decreased, as shown by MTT assay. Such effects were higher for CuO NPs with more crystalline defects and with higher ROS production than for fully crystalline NPs. At these exposure times, although NPs efficiently interacted with cell surface and were taken up by small endocytic vesicles, no ion dissolution is visible inside endo-lysosomal compartment and no effects were produced by extracellularly dissolved copper ions.

\section{Conclusions:}

A specific NP surface-dependent oxidative cell injury was demonstrated. More detailed studies are required to understand which targets precociously react to CuO NPs, but these results introduce new paradigms for the toxicity of the metal-based NPs, beyond the Trojan horse-related mechanism, and opens-up new opportunities to investigate the interactions and effects at the bio-interface for designing safer as well as more effective CuO-based biocides.

\section{Background}

The nanotechnology revolution determined, and still determines, a tremendous increase in the number and type of new engineered nanomaterials (ENMs) to which humans can be potentially exposed. Thousands of commercial articles containing ENMs are already on the market, although specific safety regulations are not yet emanated by the regulatory agencies. Carbon-based NPs and metal oxides are the most produced ENMs in the world [1] therefore the risk for humans and environment to be exposed to these compounds is quite high. 
Among metal oxide nanomaterials, zinc oxide NPs and especially copper oxide NPs have been lately investigated because of their antimicrobial properties which make them promising substitute of different toxic substances commonly used for disinfection and antimicrobial purposes. To improve their antibacterial efficacy, different synthesis techniques has been implemented. In particular, the ultrasound assisted synthesis and coating methods seem to be good candidates to obtain new antimicrobial NMs [2]. These authors hypothesized that the ability to kill bacteria depends on the generation of superoxide anions formed by the NPs coming in contact with microbial cells. During interaction with water, the above-mentioned metal oxides produce oxygen radicals which can finally damage nucleoids and membranes and are fatal to bacterial cells [2,3]. CuO-based NPs have also been suggested as powerful anticancer agents, since their ability to exert cytotoxic effects in various tumour cell lines [4] and to inhibit tumour growth in vitro and in vivo [5]. Moreover, it is well known that CuO NPs are highly toxic also to many non-target species, such as algae, crustaceans, fish, yeast, nematodes, protozoa and mammalian cell lines [6].

Almost all these studies on in vitro and in vivo systems agreed in indicating the ROS-mediated oxidative stress as the key player in the cytotoxic mechanism, but a deeper understanding of the underlying toxicity pathways and the identification of the physico-chemical properties triggering these mechanisms are mandatory in order to orient either the production of safer NMs or the development of more potent cytotoxic CuO-based nanodrugs.

With regard to the toxic behavior of CuO NPs on in vitro systems, many studies report on the very high acute toxicity in different mammalian cell lines $[5,7,8]$ with also attempts to find-out some correlations between the NP physico-chemical properties (e.g. size, shape, solubility, surface coating) and the adverse effects observed [9-12].

A size-dependent effect was observed in A549 cells, where nano-sized CuO particles resulted more effective than micron-sized ones in producing intracellular Reactive Oxygen Species (ROS) and genotoxic effects $[13,14]$.

Although metal ion dissolution can contribute to the final CuO NP-induced cytotoxicity, most papers are prone to attribute the toxic effect to the reactivity of the particles themselves. Several papers pointed-out that the contribution of the extracellularly dissolved copper ions to the CuO NP cytotoxicity accounts for less than $50 \%$ of the final effect $[15,16]$. The same authors agreed in indicating oxidative stress as a key mediator driving to cell death. Intracellular copper promotes the oxidative cascade inducing ROS production and glutathione (GSH) depletion, finally leading to DNA damage and cell death. However, the complete mechanism and the exact sequence of events occurring at cellular and sub-cellular levels are not completely understood.

Copper is a redox-active element able to cycle between different states $\left(\mathrm{Cu}^{++}\right.$and $\left.\mathrm{Cu}^{+}\right)$. The intracellular presence of both these forms coupled with the activity of intracellular enzymes participates to the 
production of different ROS including radical species (e. g. $\mathrm{H}_{2} \mathrm{O}_{2}, \mathrm{O}_{2}{ }^{\circ}{ }^{-}$and $\mathrm{OH}^{\circ}$ ) [17], which in turn interact with proteins, lipids and DNA, finally leading to apoptosis or autophagy, as proposed by $[2,18]$.

The particles' uptake by the so-called "Trojan horse" mechanism seems to play a key role in this pathway, since it allows particles to reach the intracellular compartments, where they exert their effect through the intracellular release of copper ions. By this way, the CuO NPs were seen to be internalized by endocytic vesicles, ending up in the endo-lysosomal pathway and finally engulfing secondary lysosomes where they can induce membrane leakage because of the NPs dissolution in acidic conditions, typical of the lysosomal compartment $[9,19,20]$

In a previous work, our group investigated the cell-particle interactions and effects of a commercial form of nano $\mathrm{CuO}$, in comparison with the almost inert similarly sized $\mathrm{TiO}_{2} \mathrm{NPs}$. In that work, CuO NPs displayed very high cytotoxic effects on human epithelial lung cells (A549) exposed for up to $24 \mathrm{~h}$, involving endo-lysosomal pathway activation, NP intracellular dissolution, significant increase of oxidative damages, and autophagic cell death [21].

The aim of the present work is to clarify what happens at early exposure time, trying to understand if and how NP properties, such as size and crystallinity, may directly affect precocious cell responses induced by cell-NP interaction. Our tentative is to answer the following relevant questions for the nanotoxicology field: which are the CuO NP properties mainly determining the extent of the cytotoxic response? Are internalization and intracellular dissolution of CuO NPs mandatory to trigger the cytotoxic effects?

To address these issues, we compared the effects of two CuO NPs differing in primary size, crystallinity, and ROS generation capacity, by observing the bio-interactions and effects in A549 cells exposed for $1 \mathrm{~h}$ and $3 \mathrm{~h}$. The role of oxidative stress, NP-cell interaction and endocytosis were studied by advanced molecular and morphological analyses.

\section{Results}

\subsection{CuO NPs physico-chemical properties}

As already reported, sCuO NPs were confirmed to be smaller in primary size $(24,0 \pm 0,3 \mathrm{~nm})$ by TEM analyses and displayed also a significantly higher ROS generation capacity than cCuO $(34,4 \pm 0,8 \mathrm{~nm})$ $[21,22]$.

Here CuO NPs were further analysed by HRTEM in order to investigate in depth crystallite size, shape and crystal properties. Both cCuO and sCuO appeared as aggregates of irregular shaped NPs..

The two samples appeared radically different, both morphologically and dimensionally. sCuO was very small in size, possibly flat, form leaf-like clusters up to few hundreds of nanometers and have a spotted contrast (Fig. 1a). They are randomly oriented, as testified by the selected area diffraction pattern (Fig. 1a inset). High resolution images show that coherent diffracting volumes have size no larger than few tens 
of $\mathrm{nm}$ in diameter and that the spotted contrast observable at low magnification is due to superposition of particles that generate largely spaced fringes by Moirè effects (Fig. 1b).

cCuO forms bunches of discrete NPs with roughly spherical shapes and diameter up to one hundred of nanometers or more, with average values around $50 \mathrm{~nm}$ (Fig. 1c). The larger size of $\mathrm{cCuO}$ is also testified by the electron diffraction pattern (Fig. 1c, inset), where a lower number of diffraction spots can be recognized within the same diffracting area with respect to the case of sCuO (Fig. 1a). At high magnification, cCuO shows larger coherent diffracting volumes, even if often affected by parallel bands ascribable to stacking faults or twinning, as is the case of the small nanoparticle imaged in Fig. $1 \mathrm{~d}$.

Once diluted in the cell culture medium at the tested concentrations of $25 \mu \mathrm{g} / \mathrm{mL}$ and $50 \mu \mathrm{g} / \mathrm{mL}$ at $37^{\circ} \mathrm{C}$, the CuO NP suspensions were analysed by DLS.

The analysis of the autocorrelation functions of the scattered light revealed that at least two components were necessary in Eq. 1 to fit the autocorrelation functions of the light scattered by nanoparticles supended in cell culture medium at the test concentrations. The two components corrisponded to widely different hydrodynamic radii (see Table 1) and are likely due to the single nanoparticles and to rare, large, aggregates. This hypothesis was confirmed by the maximum entropy analysis of the first order correlation functions, according to Eq. 2. The distributions of the hydrodynamic radii [see Additional file 1] show typically a single peak with a smooth tail on the large size edge. The radii distributions could be described very well by the sum of four log-normal components, so that the average hydrodynamic radii could be computed, as reported in Table 1 . These values agree well with the hydrodynamic values of the fastest component detected in the autocorrelation functions by means of a double exponential decay fit, confirming that, apart from the case of $\mathrm{cCuO}(50 \mu \mathrm{g} / \mathrm{ml})$, the major component present in the suspension is that of non-aggregated nanoparticles.

Table 1

Results of the fitting of autocorrelation functions of light scattered by CuO suspensions $\left(T=37^{\circ} \mathrm{C}\right)$.

\begin{tabular}{|c|c|c|c|c|}
\hline Sample & $R_{1}^{(h)}(\mathbf{n m})$ & $R_{2}^{(h)}(\mathbf{n m})$ & $\begin{array}{c}\text { Fractional } \\
\text { intensity } \mathrm{I}_{1} / I_{\text {tot }}\end{array}$ & $\begin{array}{c}\text { Average Radius from } \\
\text { distributions (nm) }\end{array}$ \\
\hline & \multicolumn{3}{|c|}{ Double exponential fit (Eq.1) } & Maximum entropy fit (Eq.2) \\
\hline sCuO 25 $(\mu \mathbf{g} / \mathbf{m l})$ & $210 \pm 2$ & $6300 \pm 600$ & $88 \%$ & $200_{130}^{300}$ \\
\hline sCuO 50 $(\mu \mathbf{g} / \mathbf{m l})$ & $190 \pm 2$ & $790 \pm 200$ & $77 \%$ & $420{ }_{270}^{600}$ \\
\hline cCuO 25 $(\mu \mathbf{g} / \mathbf{m l})$ & $270 \pm 10$ & $4500 \pm 1200$ & $77 \%$ & $380_{270}^{600}$ \\
\hline cCuO 50 $(\mu \mathbf{g} / \mathbf{m l})$ & $770 \pm 70$ & & $100 \%$ & $700_{570}^{900}$ \\
\hline
\end{tabular}


The fits were done either as the superposition of two exponential decay (Eq. 1) or through maximum entropy deconvolution with a distribution (Eq. 2) (see 5.2.2. DLS analyses). In the latter case, the subscript and superscript indicate the range of variability of the radius within one standard deviation.

ICP analyses were performed to assess the release of copper ions in culture medium during exposure. As summarized in Fig. 2, a concentration dependent dissolution was observed for both CuO NPs, with sCuO showing higher dissolution rates than $\mathrm{cCuO}$. The incubation duration does not seem to affect sensibly the copper dissolution.

\subsection{Cell viability}

The MTT results demonstrated a concentration- and time-dependent cytotoxicity in A549 after exposure to $\mathrm{sCuO}$ NPs (Fig. 3a, b) while only a concentration-dependent effect was seen after exposure to cCuO. Significant decrease in cell viability was already observed starting from $25 \mu \mathrm{g} / \mathrm{ml}$ of cCuO and sCuO. Although after $1 \mathrm{~h}$ exposure the effects were comparable between $\mathrm{cCuO}$ and $\mathrm{sCuO}$, after $3 \mathrm{~h}$ the viability decrease was significantly higher after cell exposure to sCuO. After $3 \mathrm{~h}$ exposure to $100 \mu \mathrm{g} / \mathrm{ml} \mathrm{sCuO}$, cell viability was almost null.

NPs themselves were responsible for the CuO-induced viability decrease, since no effects were produced by soluble copper tested at the maximum concentration $(80 \mu \mathrm{g} / \mathrm{ml})$ potentially released from the highest NP concentration $(100 \mu \mathrm{g} / \mathrm{ml})($ Fig. 3a, b).

\subsection{Oxidative stress markers}

Oxidation of protein thiols and protein carbonylation were investigated as precocious markers of reversible and irreversible oxidative damage respectively.

As shown in Fig. 4, a significant and concentration-dependent decrease in reduced protein thiol content (Fig. 4a) and an increase in protein carbonylation (Fig. 4b) were observed already after $1 \mathrm{~h}$ of exposure, especially to sCuO. At $100 \mu \mathrm{g} / \mathrm{ml}$ both cCuO and sCuO almost completely oxidized the protein thiols (data not shown), whereas at the intermediate concentrations of $25 \mu \mathrm{g} / \mathrm{ml}$ and $50 \mu \mathrm{g} / \mathrm{ml}$ the effect of the sCuO was definitely higher $(p<0,05)$.

Protein carbonylation is considered a stable index of usually irreversible protein oxidation [23] and was assessed by both immunoblotting and immunochemical method after derivatization with DNP [24].

Figure $4 \mathrm{~b}$ summarizes the CuO-induced protein carbonylation in whole-cell lysates analysed by Western immunoblotting. Both nanoparticles induced a remarkable increase, although not statistically significant, in protein carbonylation, when compared to untreated cells.

In parallel, we performed the immunocytochemical detection by fluorescence acquisition of protein carbonyls together with the NP mapping (by laser reflection mode) using confocal laser scanning microscopy [25]. After $3 \mathrm{~h}$, no carbonyl-specific signal was detected in control cells (Fig. 4c), while A549 cells exposed to cCuO NPs showed a DNP immunoreactivity, indicative of protein carbonylation, as green 
spots (AlexaFluor 488) throughout the cytoplasm (Fig. 4d). This effect was associated with the presence of scattered NPs in the cytoplasm (red pseudocolor spots). A strong carbonylation signal, likely involving the cytoplasm and the cell membrane, was shown also in the sCuO-exposed cells (Fig. 4e), although fewer NPs seemed to be internalized or adherent to the cells.

By incubating cells with the antioxidant $\mathrm{N}$-acetyl-cysteine (NAC), a significant viability recovery was achieved in A549 exposed to both CuO NPs (Fig. 5). The efficacy of the antioxidant treatment was very evident in the cells exposed to the most reactive $\mathrm{sCuO}$, for which a very effective recovery was obtained at both $25 \mu \mathrm{g} / \mathrm{ml}$ and $50 \mu \mathrm{g} / \mathrm{ml}$ (Fig. 5). This confirms that the viability decrease is triggered by an early cell oxidative imbalance and thiols may be specific targets of the CuO NP oxidative potential.

\subsection{Cell-CuO NPs bio-interactions}

Cell-particle interactions were investigated by microscopy techniques in order to better understand if and how NPs were internalized and if morphological changes occurred at early exposure stages.

The outer cell morphology and the surface interactions with NPs were analysed by SEM. When compared to control (Fig. 6a), the cCuO treated cells revealed almost unaltered cell morphology with abundant NP aggregates on the outer cell membrane, especially after $3 \mathrm{~h}$ exposure (Fig. 6b, c). Cell ultrastructure resulted preserved as well (Fig. 7b, c) and, similarly to negative- and contrary to positive-control cells (Fig. $8 \mathrm{a}, \mathrm{b}, \mathrm{c})$, no intracellular dissolution of copper after $1 \mathrm{~h}$ and $3 \mathrm{~h}$ was visualized by the rhodanine staining (Fig. 8d - g).

Many small aggregates were internalized at $1 \mathrm{~h}$ post-exposure through the formation of small endocytic buds, ending up in endosomes, including multivesicular bodies, or scattered throughout the cytoplasm and not yet fused to lysosomes to form endo-lysosomes (Fig. 7b).

On the contrary, the cell morphology of A549 cells exposed to sCuO appeared soon affected by the treatment. At $3 \mathrm{~h}$ post-exposure very condensed rounded up cells were observed as characteristic morphological effects produced by sCuO (Fig. 6d) compared to cCuO. In addition, very few NPs and NP aggregates were mapped onto cell surface (Fig. 6e) and, when present (Fig. 6f), they were very small sized in comparison with those mapped onto cCuO exposed cells.

The elemental analysis performed by EDX on selected areas, confirmed the particle aggregates as made by $\mathrm{CuO}$ (Fig. $6 \mathrm{~g}, \mathrm{~h})$ for both the particles.

Ultrastructural details of control cells are reported in Figs. 7a, e. The investigation of cell-NP interactions by TEM revealed the presence of many cCuO NPs attached to the cell membrane and several aggregates inside endocytic vesicles or scattered throughout the cytoplasm (Fig. 7b, c, d). The cell ultrastructure was not compromised, and no NPs engulfed and/or leaking from secondary lysosomes were visible.

At higher magnification, sCuO NPs internalized in A549 cells already at $1 \mathrm{~h}$ post-exposure appeared as large aggregates of very small NPs characterized by very irregular and shadowing borders (Fig. 7f). The 
cell ultrastructure resulted seriously compromised after $3 \mathrm{~h}$ exposure (Fig. 7g, h). Under the light microscope, no visible particulate material was appreciable in sCuO NPs treated cells, but a diffuse brownish color was present in the cytoplasm after $1 \mathrm{~h}$ exposure (Fig. 8h, j) and it got even more intense in the condensed apoptotic cells after $3 \mathrm{~h}$ exposure (Fig. 8i, k). This points out that enhanced biological reactivity was associated to the internalization of sCuO NPs soon after cell exposure, without the involvement of the endo-lysosomal cell digestive pathway. Differently, upon prolonged exposure to sublethal concentrations of cCuO NPs, the rhodanine staining in A549 cells was characteristically mapped in round-shaped organelles, likely corresponding to secondary lysosomes (Fig. 8c - positive control).

The morphological changes induced by cell exposure to $\mathrm{sCuO} \mathrm{NPs} \mathrm{are} \mathrm{characteristic} \mathrm{of} \mathrm{the} \mathrm{early} \mathrm{stages}$ of the apoptotic cell death. This was confirmed by the flow cytometry analyses. In fact, after $3 \mathrm{~h}$ of exposure to $\mathrm{sCuO} \mathrm{NPs} \mathrm{around} 70 \%$ of the cell population turned out to be positive to annexin V (Fig. 9c, f, i) compared to untreated cells (Fig. 9, a, d, g) and in a similar way to $\mathrm{H}_{2} \mathrm{O}_{2}$-exposed cells (Fig. 9b, e, h positive control). On the contrary, no appreciable increase in annexin V-positive cells was registered after exposure to cCuO NPs (data not shown). The flow cytometry measurements of A549 cells exposed to cCuO NPs were anyway sensibly affected by the strong laser side-scattering, likely determined by the abundant cCuO NP aggregates adhering to the cell surface, as evidenced respectively by SEM and TEM (Fig. 6b, c and Fig. 7c).

To confirm the role of NP endocytosis and the specific reactivity properties, independent from the lysosomal-enhanced NP dissolution, cell exposure to $\mathrm{cCuO}$ and sCuO NPs was repeated in presence of Cytochalasin D (CytD), which depolymerizes actin filaments and, therefore, is an inhibitor of actindependent uptake mechanisms, like phagocytosis and micropinocytosis [26] and Bafilomycin A1 (BFA1), a strong inhibitor of the lysosomal acidification by the block of the proton pump activity.

As shown in Figs. 10 and 11 both CytD and BFA1 treatments were not able to rescue cells from death after $\mathrm{cCuO}$ exposure, with exception of the slight CytD-induced viability recovery in $50 \mu \mathrm{g} / \mathrm{ml} \mathrm{cCuO}$ exposed cells (Fig. 10). In addition, cells co-incubated with sCuO and BFA1 did not show viability recovery (Fig. 11), but on the contrary, they did show an almost complete recovery in presence of CytD (Fig. 10).

\section{Discussion}

In 2008 elemental copper and its alloys have been listed as antimicrobial materials and officially recognised as the first metallic antimicrobial agents by US Environmental Protection [27]. Later this statement has been amended to include also the residual antiviral properties [28]. The enhanced antimicrobial activity of Copper oxides nanoparticles towards pathogenic microorganisms and viruses has been already displayed in several studies [29-32]. This characteristic makes copper oxides commercially applicable in paints, fabrics, agriculture and in production of medical devices to prevent potential infections [33]. Such wide use and reactivity pose many concerns for human and environmental 
health and necessary precautions should be taken to reduce the risk related to occupational or environmental exposure.

Different mechanisms of action have been suggested to explain the antimicrobial activity of CuO NPs depending on the original oxidative state of copper (I and II) in the nanomaterial and his tendency to be released in the medium, and the same properties could be partially responsible for the observed cytotoxicity in mammalian cells. Finally, a recent work performed by [34] was able to show in detail the mechanism of action of $\mathrm{Cu} / \mathrm{Cu} 5 \mathrm{Zn} 5 \mathrm{Al} 1 \mathrm{SnASW}$ through High resolution microscopical studies, against bacteria.

In the current study, we investigated the toxicity mechanisms of sonochemically synthesized CuO NPs in comparison with commercial ones, on A549 cells for very short time (1h and $3 \mathrm{~h}$ ). The aim was to 1) identify specific NP physico-chemical features responsible for the precocious toxicity (e. g. crystalline defects, surface reactivity); 2) understand the role of particle internalization and the Lysosomal Enhanced Trojan Horse mechanism at early exposure stages in inducing cell death; 3 ) define suitable and precocious marker for the NP-related oxidative effects which could be considered as key events in the view of an AOP-oriented testing strategy. These aspects are crucial to be considered for designing safer or more active biocidal agents.

\subsection{Role of P-chem properties in the precocious effects of CuO NPs}

The physical and chemical properties of metal-based nanoparticles drastically influence their toxic effects.

The particles used in this study were fully characterised by combining several techniques (HRTEM, DLS, ICP-OES), while information about ESR, XRD and DSC analyses could be found in previous works $[2,21]$.

The two CuO NPs have quite similar primary size respectively of $34,4 \pm 0,8 \mathrm{~nm}$ (nCuO) and 24,0 $\pm 0,3 \mathrm{~nm}$ (sCuO) but present a different crystalline structure, as confirmed by HRTEM, and ROS generation potential. cCuO nanoparticles appeared spherical in shape, with a smooth surface and a coherent diffraction volume of tens nanometers. Electron diffraction patterns suggest that their crystallite size is bigger than the one of sCuO, which shows indeed more structural defects as already demonstrated in a previous work by DSC analyses [2]. As previously discussed, surface defects are one of the potential triggers for ROS production, making those particles potentially more hazardous when interacting with biological structures compared to cCuO.

The presence of corners, edges, or defects (increased abrasiveness) were found positively correlated with the increase of particle toxicity, potentially because (i) the increased area helps in adsorption and binding of active compounds and (ii) the increased surface defects also increases the surface area-to-volume ratio which has a direct effect on ROS generation [35]. 
A surface with defects and corrugation it's characterised by high energy due to the presence of dangling bonds that are finally responsible of the local electron density and reactivity [36].

In addition, [37] calculated conduction bands for several metal oxide nanoparticles and they found that the value estimated for $\mathrm{CuO}$ lies in the range of biological redox potentials, suggesting that the cytotoxic effects observed for this material might depend on its ability to act as a catalyst; this material is potentially capable of accepting electrons from the oxidation of biological matter and subsequently transferring them to molecular acceptors forming reactive compounds.

The first parameter we tested to compare the two compounds was the cell viability. Although both CuO NPs were able to induce a significant and concentration dependent cytotoxicity on A549 within the first hour of exposure, $\mathrm{sCuO}$ resulted to have a greater cytotoxicity compared to $\mathrm{cCuO}$ after $3 \mathrm{~h}$ and the differences became even more visible after $6 \mathrm{~h}$ [see Additional file 2]. Together with the surface defects also the size and aggregation could have played an important role. In a recent paper [12], CuO NPs with the same primary size as $\mathrm{sCuO}$ have been shown inducing higher cytotoxicity in human epithelial cells than NPs with the same composition but smaller in size $(4 \mathrm{~nm})$, normally considered as more toxic. The results were partially attributed to the nanoparticle size itself, which probably facilitated and promoted the internalization and then the intracellular accumulation of NPs.

Besides the size, solubilisation of toxic ions is also recognized as a leading mechanism of metal-based NPs effect.

After $3 \mathrm{~h}$ of incubation in complete culture medium (CCM) in a cell-free experiment, the estimated extracellular ion release from $\mathrm{sCuO}$ was around $50 \%$ and most of it occurred within the first hour, whether only $10 \%$ was determined when $\mathrm{cCuO}(50 \mu \mathrm{g} / \mathrm{ml})$ was incubated in the same conditions.

Although we found that $\mathrm{sCuO}$ is partially soluble in CCM already during the first hours of incubation, the toxicity was practically independent from the extracellular solubility of $\mathrm{CuO}$ for both the NPs. Indeed, after exposure to copper ions at the maximum theoretical concentration released by $100 \mu \mathrm{g} / \mathrm{ml}$ CuO NPs (corresponding to $80 \mu \mathrm{g} / \mathrm{ml}$ of soluble copper) we didn't observe any reduction in cell viability and these findings agree with previous studies in which the cell death induced by $\mathrm{Cu}^{++}$exposure was significantly lower than that produced by NPs [13]. In other papers, it was even reported that the presence of small concentrations of copper could stimulate growth, as found in human glioma, astrocytoma, and neuroblastoma cells [38].

Since sCuO was more soluble than $\mathrm{cCuO}$ in culture medium and, in parallel, the observed toxicity induced by sonochemical particles themselves was higher, we can assume that the intrinsic toxic potential related to the structure reactivity of the sonochemical $\mathrm{CuO}$ itself is very high.

\subsection{Role of NPs internalization and the Lysosomal Enhanced Trojan Horse mechanism at early exposure time}


In our previous study, where A549 cells were exposed to cCuO NPs for $24 \mathrm{~h}$, we attributed the responsibility for the lysosomal destabilization and for cell autophagy processes to the oxidative burst induced by the massive intracellular copper release from CuO NPs taken up through the endo-lysosomal pathway [21].

This phenomenon, known as "Lysosome-Enhanced Trojan Horse effect" (LETH), has been suggested as a general mechanism to explain the cytotoxicity of different metal containing nanoparticles (such as metallic, metal oxide, and semiconductor NPs) [39]. In that work, authors pointed up on the role of the endocytosis as the starting point for CuO NP toxicity and identified copper ions as the main mediators. Moreover, they found that particles entering cells following the endocytic process resulted in a very strong cytotoxic effect, while particles internalised directly in the cytosol by a non-energy dependent mechanism were non-toxic.

In the present work, the attention was focused on short-term events and precocious oxidative phenomena that characterize the cytotoxic mechanism induced by CuO NPs exposure. It has been demonstrated that, at $1 \mathrm{~h}$ and $3 \mathrm{~h}$ post-exposure, the intracellular ion dissolution, involving the lysosomal compartment, was not responsible for the observed cytotoxicity since we did not detect any intracellular release (or limited) of copper ions through the rhodanine staining, in parallel to cell viability decrease. After short-term exposure we can hypothesize that for $\mathrm{cCuO}$ endocytosis works as temporary and protective mechanism to reduce particle toxicity. Cells try to modulate the stress induced by the interactions with particles through the endocytic process but, in this way, they internalise big amount of NPs, later able to release ions in the intracellular environment and to induce the cell death through LETH at later stages (24h) [21].

In sCuO-exposed A549 cells we suggest that the precocious oxidative damages observed were independent from LETH mechanism, supporting once again the idea that sCuO NPs are able to act very quickly depending on their own surface reactivity.

The first biological barrier encountered by particles is the plasma membrane, but that interaction could only partially explain the precocious cytotoxic effect induced by CuO NPs. Apparently, NP internalization is mandatory to start the cytotoxic process as confirmed by viability results obtained by co-incubating cells with NPs and cytocalasin D (CytD). This molecule is known to inhibit energy dependent mechanisms of internalisation even if the exact endocytic route seems to be cell-type specific [40, 41]. In our study, we observed a significant reduction in cell mortality only after co-incubation of $\mathrm{sCuO}(25,50$ $\mu \mathrm{g} / \mathrm{ml}$ ) with $4 \mu \mathrm{M}$ CytD. This evidence confirms that the endocytosis of particles is playing a pivotal role even in promoting the very early toxicity of sCuO.

Furthermore, blocking the proton pumps responsible for the lysosomal acidification (by pre-incubating cells with Bafilomycin A1) we did not observe any recovery in term of cell viability after exposure to both $\mathrm{CuO}$ NPs at the short exposure times used for this study. Thus, sCuO does not necessarily need to follow the lysosomal pathway or being dissolved by the surrounding acidic environment to exert its toxicity. In fact, as shown by TEM analyses, the cell ultrastructure looked affected by the presence of sCuO free aggregates, which in turn can be considered responsible of the increased level of oxidized proteins. 
Likely, these particles are more prone to generate free radicals because of their size and surface defects leading to the oxidization of macromolecules (DNA, lipids and proteins) and resulting in significant oxidative stress and cell death, as previously suggested for CuO NPs by [42].

In particular, [15] observed that CuO NPs clearly localised in both mitochondria and cell nucleus after being taken up by $A 549$ cells through endocytosis. There they stimulate ROS via impaired electron transport chain inducing structural damage, activation of NADPH-like enzyme system, and depolarization of the mitochondrial membrane [43] which then resulted in apoptosis [44].

In our study around $70 \%$ of the cell population turned out to be positive to annexin $\mathrm{V}$ after $3 \mathrm{~h}$ exposure to sCuO (by flow cytometry analysis), confirming apoptosis as main mechanism driving to cell death. Usually, cancer cells tend to avoid apoptosis and continue to propagate [45] but it has been demonstrated that increased ROS level in cancer cells alters the mitochondrial functions and plays a key role in the apoptosis induction [46-48]. Moreover, [49] found apoptosis as main mechanism of cell death in cancer cells exposed to different sizes of CuO NPs. The involvement of oxidative events in the process driving to cell death in our model was testified by the viability recovery observed in presence of NAC, which works as ROS scavenger.

Co-incubation with $\mathrm{N}$-acetyl cysteine was able to significantly prevent cytotoxicity after exposure to sCuO $(25,50 \mu \mathrm{g} / \mathrm{ml})$ even if the oxidative insult induced by the highest concentration of NPs was probably too strong to be totally inhibited thus, we cannot exclude the possibility of a direct damage provoked by the particles themselves [50].

Further investigations therefore are needed to understand the potential of $\mathrm{sCuO}$ nanoparticles to target specifically cancer cells, preserving the normal ones, in order to evaluate the possibility of applying this material as potential and effective agent in anticancer therapies, of course in combination with proper surface functionalization. The use of more realistic ad complex models like 3D co-culture systems and organoids, could additionally help in the assessing of this targeting ability.

Although the uptake of particles was observed also in cCuO- exposed cells, NP internalization seems to have a negligible contribution to the precocious cytotoxicity induced by this compound. As testified by the experiments performed co-incubating cells with particle and cytocalasin D, no significant recovery in cell viability was observed.

Only after $6 \mathrm{~h}$ of exposure, there was evidence of activation of LETH that could be responsible for later effects, here not investigated. In fact, intralysosomal dissolution of copper was detected in 6h-exposed cells, as testified by the presence of rhodanine-positive precipitate in the cytoplasm [see Additional file 3].

We know from TEM and DLS analyses that the single particle size and the hydrodynamic diameter of the commercial $\mathrm{CuO}$ are bigger than those of the sonochemical $\mathrm{CuO}$. These findings suggest a potential high deposition rate on the top of the cell layer, as also evident by our SEM analyses, with a consequent increase of interaction between particles and cellular proteins or lipids as suggested by [51]. 


\subsection{Precocious markers for CuO-induced oxidative stress}

As reported in [52], in living cells ROS as $\mathrm{H}_{2} \mathrm{O}_{2}$ and $\mathrm{O}^{2--}$ can be converted into the more reactive hydroxyl radical, $\mathrm{OH}$-, which can cause DNA-strand breaks, damage membrane lipids or attack proteins.

Proteins are particularly sensitive to the presence of ROS/RNS. The interaction between amino-acids residues with this chemical species or with different intermediates generated by the oxidation of other cellular compounds (as lipids and carbohydrates) could have repercussions on their activity, unfolding, degradation, and, ultimately, on cell functioning [53-56].

The increase in the production of reactive oxygen species (ROS) and reactive nitrogen species (RNS) plays an important role in copper-induced organic dysfunction [57]. Moreover, we already hypothesized that the precocious events involved in the early cytotoxicity of CuO could depend on CuO NP specific action against thiol groups as already suggested in [58].

For these reasons, we investigated also thiolation and carbonylation as potential markers for reversible and irreversible protein modification respectively.

Here, we have the evidence that showed how $\mathrm{nCuO}$ is powerful in inducing thiol group oxidation and protein carbonylation in A549 cells after short exposure time at high concentration $(100 \mu \mathrm{g} / \mathrm{ml})$, with sCuO retaining such effect also at lower concentrations, which testifies that the sonochemically synthesized $\mathrm{nCuO}$ is a stronger oxidating agent compared to the commercial form and that thiolation could be consider a good marker for $\mathrm{nCuO}$ precocious biological reactivity and toxicity. Decline in the levels of NPSH (non-protein thiol groups) and PSH (protein-thiol groups) were also observed in the liver and kidney as reported in [59].

In particular for sCuO we observed precocious irreversible oxidative damages to biomolecules, as confirmed by the immunochemistry of protein carbonyls, since after $3 \mathrm{~h}$-exposure a significant protein carbonylation increase was detected in A549 cells treated with $50 \mu \mathrm{g} / \mathrm{ml} \mathrm{sCuO}$. Under these exposure conditions, size reduction and morphological changes on cells were detected by SEM. Thus, our results suggest that sCuO NPs activate a cell death pathway through an oxidative stress that involves at first proteins and then lipids and is reasonably independent from extracellular and intracellular release of copper ions, but likely depends on the defects of the crystalline structure of the particles, which ultimately dictates the ability to locally generate ROS.

\section{Conclusion}

Our findings testify that the size combined with the high ROS generation potential due to the surface characteristics make sonochemically synthesized copper oxide NPs, sCuO, a powerful cytotoxic agent against A549 when compared to the commercial and more crystalline form of $\mathrm{CuO}$. Its surface defects are highly unstable zones due to the presence of unshielded, charged unbalanced atoms, and thus free bonds prone to start reactions. 
The mode of action of both the NPs in the early stage of exposure seems to be independent from the LETH (within $3 \mathrm{~h}$ ) and could be attributed to the direct interaction between the fine particles and the intracellular components for $\mathrm{s} C u O$. For $\mathrm{cCuO}$, the high tendency to aggregate increase the sedimentation of NPs on the top of the cells, making more critical the interaction between the NPs and the biological components, but they are abundantly taken up by cells through the endo-lysosomal pathway, which anyway becomes active in term of cell stress and death only at later exposure time.

For applications as cytotoxic or bactericidal agent, the high reactivity of sCuO could represent a great advantage (since with reduced amount of material is possible to obtain high performances), but its surface properties must be seriously considered in the safety-by-design frameworks.

Combined with the minimization of the environmental dispersion and a wiser risk management, the control of the intrinsic biological reactivity of the NPs could be a promising strategy for the implementation of new sCuO embedded or coated materials and devices useful to face the last biological and medical challenges of this century, including the prevention of the pathogens spreading (especially after the recent SARS-CoV-2 pandemic), without disregarding the safety aspects.

\section{Methods}

\subsection{Materials}

Anti-dinitrophenyl-KLH (anti-DNP) antibodies, rabbit IgG fraction, goat anti-rabbit IgG, and goat antimouse antibodies conjugated with Alexa 488 were purchased from Molecular Probes (Eugene, OR, USA). ECL Plus Western blotting detection reagents were obtained from GE Healthcare (Milan, Italy). Precision Plus Protein All Blue Standards, ranging from 10 to $250 \mathrm{kDa}$, were obtained from Bio-Rad Laboratories s.r.l. (Segrate, Italy). Biotin-maleimide (N-biotinoyl-N'-(6-maleimidohexanoyl) hydrazide) was purchased from Sigma-Aldrich (Milan, Italy) as well as all the other reagents of analytical grade.

\subsection{NP physical and chemical characterization}

This work is based on the comparison of the early interactions and cytotoxic effects induced by two CuO NPs differing in crystalline structure and reactive oxygen species (ROS) generation capacity. We compared commercial nanosized $\mathrm{CuO}$ (cCuO) from Sigma Aldrich (\#544868; CAS Number 1317-38-0), to sonochemically synthesized CuO NPs (sCuO) kindly provided by Prof. A. Gedanken's laboratory (Bar-llan University, Ramat-Gan, Israel). The physical and chemical properties of these NPs have been previously reported $[2,21]$. Briefly, while cCuO turned out to be fully crystalline, the sCuO NPs showed more defects and a less organized structure than cCuO. In cell-free systems, the capacity of generating ROS once in contact with water was significantly higher for sCuO NPs.

\subsubsection{HRTEM analyses}


In depth, high resolution transmission electron microscopy (HRTEM) analyses were performed at the Department of Physical Sciences, Earth and Environment of the University of Siena with a Jeol JEM 2010 instrument operating at $200 \mathrm{keV}$ and equipped with slow scan CDD camera Olympus Tengra (2304 $\mathrm{x}$ $2304 \times 14$ bit) for image acquisition. TEM samples were prepared dispersing CuO NPs in isopropylic alcohol, ultrasonicating for 3 minutes and then dropping $5 \mu \mathrm{l}$ drop of the solution on Cu-grids supporting a carbon-coated formvar membrane.

\subsubsection{DLS analyses}

The hydrated size of the nanoparticles was evaluated from the autocorrelation functions of the scattered light.

NP powders were weighted with a microbalance, suspended in ultrapure water to generate a stock suspension of $8 \mathrm{mg} / \mathrm{ml}$ and then sonicated for $5 \mathrm{~min}$ in ultrasonicator bath working at a frequency of 40 $\mathrm{kHz}$ (Sonica - Soltec). Aliquots were pipetted off the stock suspensions immediately after sonication and diluted in the cell culture medium to obtain the test concentrations of $10,25,50$ and $100 \mu \mathrm{g} / \mathrm{ml}$. The final NP suspensions at 25 and $50 \mu \mathrm{g} / \mathrm{ml}$ were analyzed in order to characterize the hydrodynamic behavior in the cell culture medium at $37^{\circ} \mathrm{C}$.

The NP suspensions were studied by a home-made DLS spectrometer [60]. The laser source was a He-Ne laser (HNL210L, Thorlabs, USA) emitting at $633 \mathrm{~nm}$ with average power $21 \mathrm{~mW}$. The temperature of a cylindrical quartz cell (Hellma GmbH \& Co, Germany) was kept under control by a thermostat (Thermo Haake $\mathrm{GmbH}$, Germany) at $37^{\circ} \mathrm{C}$. The temperature values, monitored by a thermocouple placed just below the scattering cell, had fluctuations smaller than $0.1^{\circ} \mathrm{C}$. The normalized intensity autocorrelation functions (ACFs) were computed by an ISS FCS board (ISS Inc. Urbana, IL, USA) and they were fit to a multi-exponential decay law according to the following relation [61]:

$$
g^{(2)}(\tau)=\frac{\langle I(t+\tau) I(t)\rangle_{t}}{\left\langle I^{2}(t)\right\rangle_{t}}=1+f\left(\sum_{k} A_{k} e^{-D_{k} q^{2} \tau}\right)^{2}
$$

where $D_{k}$ is the translational diffusion coefficient of the $k$-th diffusing species, $q$ is the wave vector, $q=$ $(4 \pi n / \lambda) \sin (\theta / 2), n$ is the refraction index of the solution, taken equal to that of water at the experimental temperature, $\lambda=633 \mathrm{~nm}$ is the laser light wavelength and $\theta=90 \mathrm{deg}$ is the scattering angle. The parameter $f$ depends on the ratio between the detector and the coherence area and was left as a free fitting parameter (typically $f=0.25-0.5$ ). The values of $D_{k}$ provide us the average size of the $k$-th diffusing species, according to the Einstein relation 


$$
D_{k}=\frac{K_{B} T}{6 \pi \eta R_{k}^{(h)}},
$$

where $K_{B}$ is the Boltzmann constant, $T$ and $\eta$ are the solution temperature and viscosity and is the hydrodynamic radius of the $k$-th species. We verified that two components with widely different diffusion coefficients were necessary to fit the data. Alternatively, we analyzed the first order correlation functions by applying maximum entropy methods [62] to obtain the distributions of hydrodynamic radii. In this case, the intensity (second order) correlation function was converted in the first order correlation function (1) and the analysis was performed on $g^{(1)}=\tau$ up to the first largest lag-time, $\tau^{*}$, for which $g^{(2)}=\tau^{*}<1$. The first order correlation function was fit to a regularized distribution of relaxation rates () according to [63]:

$$
g^{(1)}(\tau)=\int P(\Gamma) \exp (-\Gamma \tau) d \ln (\Gamma)
$$

\subsubsection{NP dissolution}

To measure the NP dissolution in the cell culture medium, Inductively Coupled Plasma Optical Emission Spectrometry (ICP-OES) analyses were performed. After $1 \mathrm{~h}$ and $3 \mathrm{~h}$ incubation with $\mathrm{cCuO}$ and $\mathrm{sCuO}$ at $25-50 \mu \mathrm{g} / \mathrm{ml}$, cell culture medium was collected and ultra-filtrated using centrifuge tubes VIVASPIN 20 with a molecular weight cut-off of 10,000 Da (Sartorius Stedim Biotech $\mathrm{GmbH}$, Goettingen, Germany).

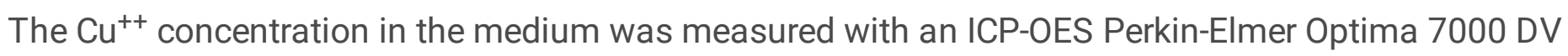
(Perkin-Elmer, Santa Clara, CA, USA).

\subsection{Cell cultures and treatments}

The in vitro studies were performed using the human alveolar epithelial cell line A549 (American Type Culture Collection, ATCC).

A549 cells were grown in OptiMEM medium supplemented with heat-inactivated $10 \%$ foetal bovine serum (FBS) and mixture of antibiotics (penicillin $50 \mathrm{U} / \mathrm{ml}$ and streptomycin $50 \mu \mathrm{g} / \mathrm{ml}$ ) at $37^{\circ} \mathrm{C}$, in a $5 \% \mathrm{CO}_{2}$ humidified atmosphere.

For viability and biochemical assays, cells were seeded at a density of 1,6 $610^{5}$ /well in 6 multi-well plates. For transmission electron microscopy, cells were seeded at a density of $1,35 \times 10^{5}$ in $\varnothing 3.5 \mathrm{~cm}$ sterile plastic petri dishes. For light, confocal and scanning electron microscopy cells, were seeded and processed on sterilized glass coverslips. 
Once the monolayer had reached $70-80 \%$ confluence, cell culture medium was mixed with aliquots of the NP suspensions prepared in sterile milliQ water, in order to generate the final NP working concentrations of $10,25,50$ and $100 \mu \mathrm{g} / \mathrm{ml}$. The exposure times were $1 \mathrm{~h}$ and $3 \mathrm{~h}$.

To reduce as much as possible the interference of protein adsorption onto NP surface, BSA- and serumfree cell culture medium was used to prepare NP working suspensions. $\mathrm{CuSO}_{4} \cdot 5 \mathrm{H}_{2} \mathrm{O}$ in sterile milliQ water was used to prepare prior to each experiment $80 \mu \mathrm{g} / \mathrm{ml} \mathrm{Cu}^{++}$solution and used immediately.

\subsection{Cell viability}

The viability was assessed by MTT assay in cells exposed to cCuO and sCuO at $10-100 \mu \mathrm{g} / \mathrm{ml}$ for $1 \mathrm{~h}, 3$ $\mathrm{h}$ and $6 \mathrm{~h}$. The contribution to cytotoxicity of copper ions was also evaluated by using $\mathrm{CuSO}_{4}$ salt at a $\mathrm{Cu}^{++}$concentration corresponding to maximum theoretical concentration achievable from the complete particle dissolution at the highest NP concentration tested $(100 \mu \mathrm{g} / \mathrm{ml})$. Untreated cells were used as negative control.

At the end of exposure, culture medium was replaced with new medium containing MTT solution (0.3 $\mathrm{mg} / \mathrm{ml}$ ) and incubated for 2.5 hours at $37^{\circ} \mathrm{C}$. The formazan crystals formed were dissolved in dimethyl sulfoxide (DMSO). The plates were shacked for $10 \mathrm{~min}$ at room temperature and optical density was recorded at $570 \mathrm{~nm}$ (using $690 \mathrm{~nm}$ as a reference) by a multiplate reader (Multiskan Ascent, Thermo Electron Corporation, Vantaa, Finland).

The results were representative of at least three independent experiments. Statistical comparisons were performed by one-way ANOVA followed by a post-hoc test.

\subsection{Cell oxidative markers}

A549 cells were exposed to CuO NPs or copper salt under the same conditions used for MTT assay. Cigarette smoke extract (CSE) at 10\%, prepared as previously described [64], and $500 \mu \mathrm{M} \mathrm{HOCl}$ were used as positive controls for protein carbonylation and protein $\mathrm{SH}$-group oxidation, respectively.

At the end of the exposure to CuO NPs or copper salt, cell monolayers were rinsed two times in PBS, recovered by mechanical scraping and lysed in RIPA buffer added with a protease inhibitors cocktail. Cell lysates were centrifuged at 11,000 rpm for 4 min and then sonicated on ice 3 times for 10 s each using a Sanyo Soniprep ultrasonicator (5 $\mu \mathrm{M}$ amplitude).

Samples were centrifuged at 20,000 g for 5 min to remove NPs, and the supernatants were collected and immediately stored at $-20^{\circ} \mathrm{C}$, until further biochemical analyses.

\subsubsection{Protein carbonylation}

Carbonylated proteins were derivatized with 2,4-dinitrophenylhydrazine (DNPH). $200 \mu \mathrm{g}$ proteins in lysis buffer (final concentration $1 \mathrm{mg} / \mathrm{ml}$ ) were mixed with $40 \mu \mathrm{l}$ of $10 \mathrm{mM} \mathrm{DNPH}$ in $2 \mathrm{~N} \mathrm{HCl}$ and incubated for $60 \mathrm{~min}$ in the dark with frequent vortexing. After derivatization, protein samples were mixed with $240 \mu \mathrm{L}$ 
of $20 \%$ trichloroacetic acid (TCA) and incubated for $10 \mathrm{~min}$ in ice. After centrifugation at 20,000 g per 15 min at $4^{\circ} \mathrm{C}$, protein pellets were washed three times with 1:1 ethanol/ethylacetate to remove free DNPH. After air-drying, pellets were resuspended in $2 \times$ reducing Laemmli sample buffer. Proteins were separated by SDS-PAGE ( $12 \%$ Tris- $\mathrm{HCl}$ resolving gel) and transferred to polyvinylidene difluoride (PVDF) membrane. Derivatized proteins were detected by Western immunoblotting with anti-dinitrophenyl-KLH (anti-DNP) antibody. In particular, PVDF membrane was washed in PBST (10 mM Na phosphate, pH 7.2, $0.9 \%(\mathrm{w} / \mathrm{v}) \mathrm{NaCl}, 0.1 \%(\mathrm{v} / \mathrm{v})$ Tween-20) and blocked for $1 \mathrm{~h}$ in $5 \%(\mathrm{w} / \mathrm{v})$ non-fat dry milk in PBST. After washing three times with PBST for 5 min each, carbonyl formation was probed by a 2-h incubation with $5 \%$ milk/PBST containing anti-DNP antibodies (1:40,000 dilution). After three washes with PBST for 5 min each, the membrane was incubated with a 1:80,000 dilution of the secondary antibody linked to horseradish peroxidase (HRP) in 5\% milk/PBST for $1 \mathrm{~h}$. After washing three times with PBST for $5 \mathrm{~min}$ each, immunostained protein bands were visualized with enhanced chemiluminescence detection (ECL).

\subsubsection{Immunocytochemical detection of protein carbonyls}

After $3 \mathrm{~h}$ of exposure to 25 and $50 \mu \mathrm{g} / \mathrm{ml}$ of $\mathrm{cCuO}$ and sCuO, cell monolayers were fixed in methacarn, derivatized with DNPH solution ( $0.1 \% \mathrm{v} / \mathrm{v}$ in $2 \mathrm{M} \mathrm{HCl}$ for $1 \mathrm{~h})$ and unspecific sites were blocked with NGS. Cells were then incubated with the monoclonal anti-dinitrophenyl antibody (Sigma, Saint Louis, USA) and the signal retrieving was achieved by an AlexaFluor-488 conjugated goat anti-mouse secondary antibody (Molecular Probes). Nuclei were stained with $5 \mu \mathrm{M}$ DRAQ5 ${ }^{\mathrm{TM}}$ (ThermoFisher Scientific).

Slides were finally mounted in Prolong Gold Anti-fade mounting medium (Molecular Probes) and observed with a Leica TCS SP5 confocal microscope. Reflected-light optics were used at a magnification of 40x (1.25 NA Plan-Apochromat). Samples were illuminated with a $488 \mathrm{~nm}$ Argon/Krypton laser, using an intensity of the AOTF filter by $10 \%$. Images were processed with the Leica dedicated LAS AF software.

\subsubsection{Protein Sulphydryl Oxidation}

Sample proteins were derivatized with biotin-maleimide. $100 \mu \mathrm{g}$ proteins in lysis buffer (final concentration $1 \mathrm{mg} / \mathrm{ml}$ ) were mixed with $75 \mu \mathrm{M}$ of biotin-maleimide and incubated for $60 \mathrm{~min}$ in the dark with frequent vortexing. After derivatization, protein samples were mixed with a volume of $2 \times$ reducing Laemmli sample buffer. Proteins were separated by SDS-PAGE (12\% Tris- $\mathrm{HCl}$ resolving gel) and transferred to PVDF membrane. Derivatized proteins were detected by Western blotting. PVDF membrane was washed in PBST and blocked for $1 \mathrm{~h}$ in $5 \%(\mathrm{w} / \mathrm{v})$ non-fat dry milk in PBST. After washing three times with PBST for 5 min each, protein sulphydryl oxidation was probed by a $2 \mathrm{~h}$ incubation with $5 \%$ milk/PBST containing streptavidin linked to HRP (1:5,000 dilution). After three washes with PBST for 5 min each stained protein bands were visualized with ECL. Densitometric analysis of both protein carbonylation and sulphydryl oxidation was performed by scanning the chemiluminescence film images and using the Image J 1.40d software (National Institutes of Health, USA).

\subsection{Copper cytochemistry}


Intracellular copper ion dissolution was determined by a cytochemical method using rhodanine. After being formalin fixed, control and CuO NP-exposed cells were incubated with $0.12 \mathrm{~g} / \mathrm{l}$ rhodanine ( $\mathrm{p}$ Dimethylaminobenzylinene-rhodanine) alcoholic solution, abundantly rinsed and nuclei were counterstained with haematoxylin. Slides were mounted in a glycerol-based medium and immediately observed under the light microscope (Axioplan - Zeiss).

\subsection{Cytofluorimetric analysis of cell death}

This analysis was performed both by flow cytometer and fluorescence microscope according to the instructions on the provided protocol (Annexin V, Alexa Fluor ${ }^{\circledR} 488$ Conjugate, Thermo Fisher Scientific). Briefly, after $3 \mathrm{~h}$ of exposure to nCuO NPs cells were washed twice with PBS, detached using trypsin and then incubated with the Annexin $\mathrm{V}$ and/or propidium iodide $\mathrm{PI}$ ) reagent for $15 \mathrm{~min}$ in the dark. Positive controls were treated with $10 \mathrm{mM} \mathrm{H}_{2} \mathrm{O}_{2}$. The fluorescence signal was analysed by a Becton Dickinson FACS Calibur flow cytometer immediately after the adding of $400 \mu \mathrm{g} / \mathrm{l}$ of $1 \mathrm{X}$ Annexin binding buffer to each sample.

For the microscopic evaluation, cells were grown on coverslips, exposed to NPs and then incubated with the Annexin V or/and PI reagents. Coverslips were mounted on slides and immediately observed under a Zeiss Axio-Observer Z1 equipped with an AxioCam MRc. Digital images were elaborated by the dedicated AxioVision Rel. 4.8 software.

\subsection{Electron microscopy}

SEM analyses were performed to investigate the ultrastructural modifications and the cell-particle interactions on the cell surface. Cell monolayers grown on coverslips were fixed in $2 \%$ glutaraldehyde prepared in cacodilate buffer, post-fixed with $1 \% \mathrm{OsO}_{4}$ first dehydrated in a graded ethanol series followed by a Hexamethyldisilazane (HMDS) graded series (25-50-75-100\%). Coverslips were then mounted onto standard SEM stubs, coated with pure gold and observed under a Zeiss LEO 1430 scanning electron microscope operating at an accelerating voltage of $20 \mathrm{kV}$.

TEM analyses were conducted to study the ultrastructural modifications and to visualize the NPs in the subcellular compartments. Cell monolayers were fixed in $2.5 \%$ glutaraldehyde in cacodilate buffer, postfixed with $1 \% \mathrm{OsO}_{4}$ and routinely embedded in EPON-Araldite resin. Frontal $60 \mathrm{~nm}$ ultrathin sections of the cell layers were cut on a Reichert Jung ultramicrotome, collected onto 300 mesh copper grids and finally observed with a Jeol JEM1220 transmission electron microscope, operating at an accelerating voltage of $80 \mathrm{kV}$ and equipped with a Lheritier digital camera. To prevent metal salt contamination and allow a clear NP visualization in cells, pre- and post-embedding stains were avoided.

\section{Statistics}

All data are presented as the mean \pm standard deviation (SD) of at least three biological replicates unless otherwise specified. Statistical analysis was done using SigmaStat software. A one-way analysis of 
variance (ANOVA) with a subsequent Fischer's LSD post-hoc test was performed. Differences between values were considered statistically significant when $P<0.05\left({ }^{*}, \#\right)$.

\section{Abbreviations}

AOTF acousto-optic tunable filter

AOP adverse outcome pathway

ATCC American type culture collection

BFA1 bafilomycin A1

BSA bovine serum albumin

CCM complete culture medium

CLSM confocal laser scanning microscopy

Cu copper

$\mathrm{Cu}^{+}, \mathrm{Cu}^{++}$copper ions

SARS-CoV-2 severe Acute respiratory syndrome coronavirus 2

CSE cigarette smoke extract

CytD cytochalasin D

DLS dynamic light scattering

DNA deoxyribonucleic acid

DMSO dimethyl sulfoxide

DNP protein-conjugated dinitrophenylhydrazones

DNPH 2,4-dinitrophenylhydrazine

DSC differential scanning calorimetry

ECL enhanced chemiluminescence detection

EDX energy dispersive X-ray analysis

ENMs engineered nanomaterials 
EPA US environmental protection agency

ESR electron spin resonance spectroscopy

FACS fluorescence-activated cell sorting

FBS foetal bovine serum

FSC-H forward scattering

FITC fluorescein isothiocyanate detection

HMDS hexamethyldisilazane

$\mathrm{H}_{2} \mathrm{O}_{2}$ : hydrogen peroxide

HOCl: hypochlorous acid

HRP horseradish peroxidase

HRTEM high resolution transmission electron microscopy

ICP-OES inductively coupled plasma-optical emission spectroscopy

LETH lysosome-enhanced trojan horse effect

MTT 3-(4,5-dimethylthiazol-2-yl)-2,5-diphenyltetrazolium bromide

NAC N-acetyl-cysteine

NADPH nicotinamide adenine dinucleotide phosphate

NGS normal goat serum

NMs nanomaterials

NPs nanoparticles

NPSH non-protein thiol groups

${ }_{1} \mathrm{O}_{2}$ : singlet oxygen

$\mathrm{O}_{2}{ }^{\circ}$ : superoxide anion

$\mathrm{OH}^{\circ}$ : hydroxyl radical

PBS phosphate buffer solution 
PBST phosphate buffer solution-tween

PCO protein carbonyls

PSH protein-thiol groups

PI propidium iodide

PVDF polyvinylidene difluoride

RIPA radioimmunoprecipitation assay buffer

ROS reactive oxygen species

SDS-PAGE sodium dodecyl sulphate - polyacrylamide gel electrophoresis

SEM scanning electron microscopy

SSC-H side scattering

TCA trichloroacetic acid

TEM transmission electron microscopy

XRD x-ray diffraction

\section{Declarations}

Ethics approval and consent to participate

Not applicable

Consent for publication

Not applicable

\section{Availability of data and materials}

Authors can confirm that all relevant data are included in the article and/or its additional information files. Detailed datasets used and/or analysed during the current study are available from the corresponding author [PM] on reasonable request.

\section{Competing interests}

The authors declare that they have no competing interests.

\section{Funding}


The research was supported by Fondazione Cariplo through the project OverNanoTox (2013-0987), by the European Community through the project PROTECT (H2020-720851, Pre-commercial lines for production of surface nanostructured antimicrobial and anti-biofilm textiles, medical devices, and water treatment membranes) and by the Italian Ministry of University and Research (MUR) through the project AMROCE (APJTC2020_00098, AquaticPollutants Joint Transnational Call 2020, Nanoenabled strategies to reduce the presence of contaminants of emerging concern in aquatic environment).

\section{Author's contribution}

EM performed most of the experimental work, took care of data analysis, produced all figures and tables and wrote the manuscript. GColombo run the experiments on reduced protein thiol oxidation and protein oxidative damage quantification. GCapitani performed the HRTEM analysis and performed the relative image analysis. GChirico did the NP-characterization by DLS and performed the relative data analysis. IDD participated in experimental planning and data analysis related to protein oxidation. PM coordinated the experimental work, contributed to the manuscript drafting and supervised the final version.

All the authors have read and approved the submitted version.

\section{Acknowledgments}

The authors thank Maria Tringali (Dept. of Environmental Science, University Milano Bicocca) for the ICPOES analyses on cell culture medium samples, Daniele Gallinotti and Cristiano Dibenedetto respectively for the TEM and SEM picture acquisition.

sCuO NPs were kindly provided by Prof. Aharon Gedanken (Bar-Ilan University, Ramat-Gan, Israel).

\section{References}

1. Sun T, Yan Y, Zhao Y, Guo F, Jiang C. Copper oxide nanoparticles induce autophagic cell death in A549 cells. PLoS One. 2012;7(8):e43442.

2. Perelshtein I, Lipovsky A, Perkas N, Gedanken A, Moschini E, Mantecca P. The influence of the crystalline nature of nano-metal oxides on their antibacterial and toxicity properties. Nano Res. 2015;8:695-707.

3. Applerot G, Lellouche J, Lipovsky A, Nitzan Y, Lubart R, Gedanken A, Banin E. Understanding the antibacterial mechanism of $\mathrm{CuO}$ nanoparticles: revealing the route of induced oxidative stress. Small. 2012;8:3326-3337.

4. Yuan et al., 2016

5. Benguigui M, Weitz IS, Timaner M, Kan T, Shechter D, Perlman O, et al. Copper oxide nanoparticles inhibit pancreatic tumor growth primarily by targeting tumor initiating cells. Sci Rep. 2019;9:12613.

6. Bondarenko O, Juganson K, Ivask A, Kasemets K, Mortimer M, Kahru A. Toxicity of Ag, CuO and ZnO nanoparticles to selected environmentally relevant test organisms and mammalian cells in vitro: $\mathrm{A}$ 
critical review. Arch Toxicol. 2013;87:1181-1200.

7. Fahmy B, Cormier SA. Copper oxide nanoparticles induce oxidative stress and cytotoxicity in airway epithelial cells. Toxicol In Vitro. 2009;23:1365-1371.

8. Ivask A, Titma T, Visnapuu M, Vija H, Käkinen A, Sihtmäe M, et al. Toxicity of 11 metal oxide nanoparticles to three mammalian cell types in vitro. Curr Top Med Chem. 2015;15:1-16.

9. Studer A, Limbach LK, Van Duc L, Krumeich F, Athanassiou EK, Gerber LC, et al. Nanoparticle cytotoxicity depends on intracellular solubility: comparison of stabilized copper metal and degradable copper oxide nanoparticles. Toxicol Lett. 2010;197:169-174.

10. Di Bucchianico S, Fabbrizi MR, Misra SK, Valsami-Jones E, Berhanu D, Reip P, et al. Multiple cytotoxic and genotoxic effects induced in vitro by differently shaped copper oxide nanomaterials. Mutagenesis. 2013;28(3):287-299.

11. Semisch A, Ohle J, Witt B, Hartwig A. Cytotoxicity and genotoxicity of nano - and microparticulate copper oxide: role of solubility and intracellular bioavailability. Part Fibre Toxicol. 2014;11:10.

12. Wongrakpanich A, Mudunkotuwa IA, Geary SM, Morris AS, Mapuskar KA, Spitz DR, et al. Sizedependent cytotoxicity of copper oxide nanoparticles in lung epithelial cells. Environ Sci Nano. 2016;3:365.

13. Karlsson HL, Cronholm P, Gustafsson J, Moller L. Copper oxide nanoparticles are highly toxic: a comparison between metal oxide nanoparticles and carbon nanotubes. Chem Res Toxicol. 2008;21:1726-1732.

14. Karlsson HL, Gustafsson J, Cronholm P, Moller L. Size-dependent toxicity of metal oxide particles-A comparison between nano- and micrometer size. Toxicol Lett. 2009;188:112-118.

15. Wang Z, Li N, Zhao J, White JC, Qu P, Xing B. CuO nanoparticle interaction with human epithelial cells: cellular uptake, location, export, and genotoxicity. Chem Res Toxicol. 2012;25:1512-1521.

16. Hanagata N, Zhuang F, Connolly S, Li J, Ogawa N, Xu M. Molecular responses of human lung epithelial cells to the toxicity of copper oxide nanoparticles inferred from whole genome expression analysis. ACS Nano. 2011;5:9326-9338.

17. Halliwell B. Free-radicals and metal-ions in health and disease. Proc Nutr Soc. 1987;46:13-26.

18. Laha D, Pramanik A, Maity J, Mukherjee A, Pramanik P, Laskar A, et al. Interplay between autophagy and apoptosis mediated by copper oxide nanoparticles in human breast cancer cells MCF7. Biochim Biophys Acta. 2014;1840(1):1-9.

19. Limbach LK, Wick P, Manser P, Grass RN, Bruinink A, Stark WJ. Exposure of engineered nanoparticles to human lung epithelial cells: influence of chemical composition and catalytic activity on oxidative stress. Environ Sci Technol. 2007;41:4158-4163.

20. Karlsson HL, Cronholm P, Hedberg Y, Tornberg M, De Battice L., Svedhem S, et al. Cell membrane damage and protein interaction induced by copper containing nanoparticles-Importance of the metal release process. Toxicology. 2013;313:59-69. 
21. Moschini E, Gualtieri M, Colombo M, Fascio U, Camatini M, Mantecca P. The modality of cell-particle interactions drives the toxicity of nanosized $\mathrm{CuO}$ and $\mathrm{TiO}_{2}$ in human alveolar epithelial cells. Toxicol Lett. 2013;222:102-116.

22. Perelshtein I, Ruderman Y, Perkas N., Beddow J, Singh G, Vinatoru M, et al. The sonochemical coating of cotton withstands 65 washing cycles at hospital washing standards and retains its antibacterial properties. Cellulose. 2013;20:1215-1221.

23. Dalle-Donne I, Aldini G, Carini M, Colombo R, Rossi R, Milzani A. Protein carbonylation, cellular dysfunction, and disease progression. J Cell Mol Med. 2006; 10(2):389-406.

24. Colombo G, Clerici M, Garavaglia ME, Giustarini D, Rossi R, Milzani A, et al. A step-by-step protocol for assaying protein carbonylation in biological samples. J Chromatogr B Analyt Technol Biomed Life Sci. 2016;1019:178-90.

25. Prins FA, Cornelese-ten Velde I, de Heer E. Reflection contrast microscopy: the bridge between light and electron microscopy. In: Taatjes DJ., Mossman B, Totowa T, editors. Cell imaging techniques. Methods and Protocols. Humana Press Inc., New York (USA); 2006. p. 363-401.

26. Doherty GJ, McMahon HT. Mechanisms of endocytosis. Annu Rev Biochem. 2009; 78:857-902.

27. EPA. Antimicrobial Copper Alloys. 2013. Available online:

https://www3.epa.gov/pesticides/chem_search/ppls/085353-00003-20130103.pdf (accessed on 6 Dec 2021).

28. EPA. Antimicrobial Copper Alloys. 2013. Available online:

https://www3.epa.gov/pesticides/chem_search/ppls/082012-00001-20210110.pdf (accessed on 6 Dec 2021).

29. Borkow G, Okon-Levy N, Gabbay J. Copper oxide impregnated wound dressing: biocidal and safety studies. Wounds. 2010;12:301-310. PMID: 25901580.

30. Amiri M, Etemadifar Z, Daneshkazemi A, Nateghi M. Antimicrobial Effect of Copper Oxide Nanoparticles on Some Oral Bacteria and Candida Species. J Dent Biomater. 2017;4(1):347-352.

31. Vincent M, Duval RE, Hartemann P, Engels-Deutsch M. Contact killing and antimicrobial properties of copper. J Appl Microbiol. 2017;124:1032-1046.

32. Tavakoli A, Hashemzadeh MS. Inhibition of herpes simplex virus type 1 by copper oxide nanoparticles. J Virol Methods. 2020;275:113688.

33. Meghana S, Kabra P, Chakraborty S, Padmavathy N. Understanding the pathway of antibacterial activity of copper oxide nanoparticles. RSC Adv. 2015;5:12293-12299.

34. Chang T, Prasath Babu R, Zhao W, Magnus Johnson C., Hedström P, Odnevall I, et al. High-Resolution Microscopical Studies of Contact Killing Mechanisms on Copper-Based Surfaces. ACS Appl Mater Interfaces. 2021;13(41):49402-49413.

35. Slavin YN, Asnis J, Häfeli UO, Bach H. Metal nanoparticles: understanding the mechanisms behind antibacterial activity. J Nanobiotechnol. 2017;15:65. 
36. Cademartiri L, Ozin GA. Concepts of Nanochemistry. WILEY-VCH Verlag GmbH \& Co. KGaA, Weinheim;2009.

37. Burello E, Worth AP. A theoretical framework for predicting the oxidative stress potential of oxide nanoparticles. Nanotoxicology. 2011;5(2)228-235.

38. Watt NT, Hooper NM. The response of neurones and glial cells to elevated copper. Brain Res Bull. 2001;55(2):219-224.

39. Sabella S, Carney RP, Brunetti V, Malvindi MA, Al-Juffali N, Vecchio G, et al. General mechanism for intracellular toxicity of metal-containing nanoparticles. Nanoscale. 2014;6:7052-7061.

40. Dutta D, Donaldson JG. Search for inhibitors of endocytosis Intended specificity and unintended consequences. Cell Logist. 2012;2(4):203-208.

41. Kuhn DA, Vanhecke D, Michen B, Blank F, Gehr P, Petri-Fink A, et al. Different endocytotic uptake mechanisms for nanoparticles in epithelial cells and macrophages. Beilstein $\mathrm{J}$ Nanotechnol. 2014;24(5):1625-36.

42. Akhtar MJ, Kumar S, Alhadlaq HA, Alrokayan SA, Abu-Salah KM, Ahamed M. Dose-dependent genotoxicity of copper oxide nanoparticles stimulated by reactive oxygen species in human lung epithelial cells. Toxicol Ind Health. 2016;32(5):809-821.

43. Manke A, Wang L, Rojanasakul Y. Mechanisms of Nanoparticle-Induced Oxidative Stress and Toxicity. Biomed Res Int. 2013;2013:942916.

44. Jing X, Hong Park J, Peters TM, Thorne PS. Toxicity of copper oxide nanoparticles in lung epithelial cells exposed at the air-liquid interface compared with in vivo assessment. Toxicol In Vitro. 2015;29(3):502-511.

45. Shafagh M, Rahmani F, Delirezh N. CuO nanoparticles induce cytotoxicity and apoptosis in human K562 cancer cell line via mitochondrial pathway, through reactive oxygen species and P53. Iran J Basic Med Sci. 2015; 18:993-1000.

46. Roy D, Sarkar S, Felty Q. Levels of IL-1 beta control stimulatory/inhibitory growth of cancer cells. Front Biosci. 2006;11:889-98.

47. Higuchi M, Honda T, Proske RJ, Yeh ETH. Regulation of reactive oxygen species-induced apoptosis and necrosis by caspase 3-like proteases. Oncogene. 1998;17:2753-2760.

48. Ghaleh HEG, Zarei L, Motlagh BM, Jabbari N. Using CuO nanoparticles and hyperthermia in radiotherapy of MCF-7 cell line: synergistic effect in cancer therapy. Artif Cells Nanomed Biotechnol. 2019;47(1):1396-1403.

49. Kukia NR, Abbasi A, Abtahi Froushani SM. Copper Oxide Nanoparticles Stimulate Cytotoxicity and Apoptosis in Glial Cancer Cell Line. Dhaka Univ J Pharm Sci. 2018;17(1):105-111.

50. Angelé-Martínez C, Nguyen KVT, Ameer FS, Anker JN, Brumaghim JL. Reactive Oxygen Species Generation by Copper(II) Oxide Nanoparticles Determined by DNA Damage Assays and EPR Spectroscopy. Nanotoxicology. 2017;11(2): 278-288. 
51. Thit A, Selck H, Bjerregaard HF. Toxicity of $\mathrm{CuO}$ nanoparticles and $\mathrm{Cu}$ ions to tight epithelial cells from Xenopus laevis (A6): effects on proliferation, cell cycle progression and cell death. Toxicol In Vitro. 2013(5):1596-1601.

52. Thit A, Selck H, Bjerregaard HF. Toxic mechanisms of copper oxide nanoparticles in epithelial kidney cells. Toxicol In Vitro. 2015;29:1053-1059.

53. Colombo G, Clerici M, Giustarini D, Rossi R, Milzani A, Dalle-Donne I. Redox albuminomics: oxidized albumin in human diseases. Antioxid Redox Signal. 2012;17(11):1515-1527.

54. Bachi A, Dalle-Donne I, Scaloni A. Redox proteomics: chemical principles, methodological approaches and biological/biomedical promises. Chem Rev. 2013;113(1):596-698.

55. Di Domenico F, Head E, Butterfield DA, Perluigi M. Oxidative Stress and Proteostasis Network: Culprit and Casualty of Alzheimer's-Like Neurodegeneration. Adv Geriatr. 2014;2014:527518.

56. Attri P, Kumar N, Park JH, Kumar Yadav D, Choi S, Uhm HS, et al. Influence of reactive species on the modification of biomolecules generated from the soft plasma. Sci Rep. 2015;5:8221.

57. Hejazy M, Koohi MK, Bassiri Mohamad Pour A, Najafi D. Toxicity of manufactured copper nanoparticles - A review. Nanomed Res J. 2018;3(1):1-9.

58. Chen TY, Chen SF, Sheu HS, Yeh CS. Reactivity of laser-prepared copper nanoparticles: oxidation of thiols to disulfides. J Phys Chem B. 2002;106:9717-9722.

59. Naz S, Gul A, Zia M. Toxicity of copper oxide nanoparticles: a review study IET Nanobiotechnol. 2020;14(1):1-13.

60. Chirico G, Beretta S, Baldini G. Conformation of interacting lysozyme by polarized and depolarized light scattering. J Chem Phys. 1999;110:2297-2304.

61. Berne BJ, Pecora R. Dynamic light scattering: with applications to chemistry, biology, and physics. Dover Publications Inc, New York;2000.

62. Livesey AK, Licinio P, Delaye M. Maximum entropy analysis of quasielastic light scattering from colloidal dispersions. J Chem Phys. 1986;(84):5102.

63. Steinbach PJ, lonescu R, Matthews CR. Analysis of Kinetics using a Hybrid Maximum Entropy/nonlinear-least-squares method: application to protein folding. Biophys J. 2002;82:22442255.

64. Gornati R, Colombo G, Clerici M, Rossi F, Gagliano N, Riva C, et al. Protein carbonylation in human endothelial cells exposed to cigarette smoke extract. Toxicol Lett. 2013;218(2):118-128.

\section{Figures}




\section{Figure 1}

TEM images of CUO NPs.

(a) Bright field image of sCuO NPs and related diffraction pattern (inset). (b) High resolution image of NPs as those reported in (a). (c) Bright field image of cCuO NPs and related diffraction pattern (inset). (d) High resolution image of a small nanoparticle showing twinning bands. 
$\because \mathrm{cCuO} \backsim \mathrm{sCuO}$

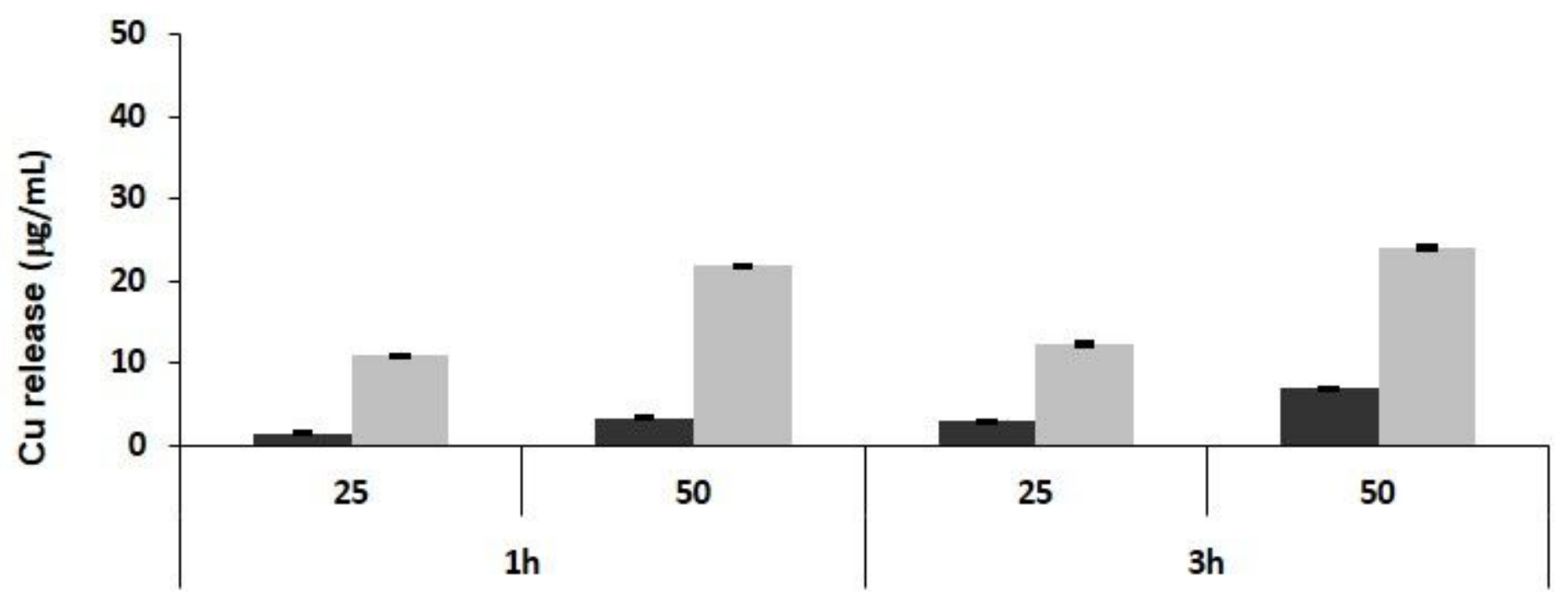

Figure 2

Extracellular copper ions release.

The amount of copper $\left(\mathrm{Cu}^{++}\right)$released by cCuO and sCuO $(25 \mathrm{mg} / \mathrm{ml}, 50 \mathrm{mg} / \mathrm{ml})$ in cell culture medium was determined by ICP-OES after $1 \mathrm{~h}$ and $3 \mathrm{~h}$ of incubation. 
$\square \mathrm{cCuO}=\mathrm{sCuO}$

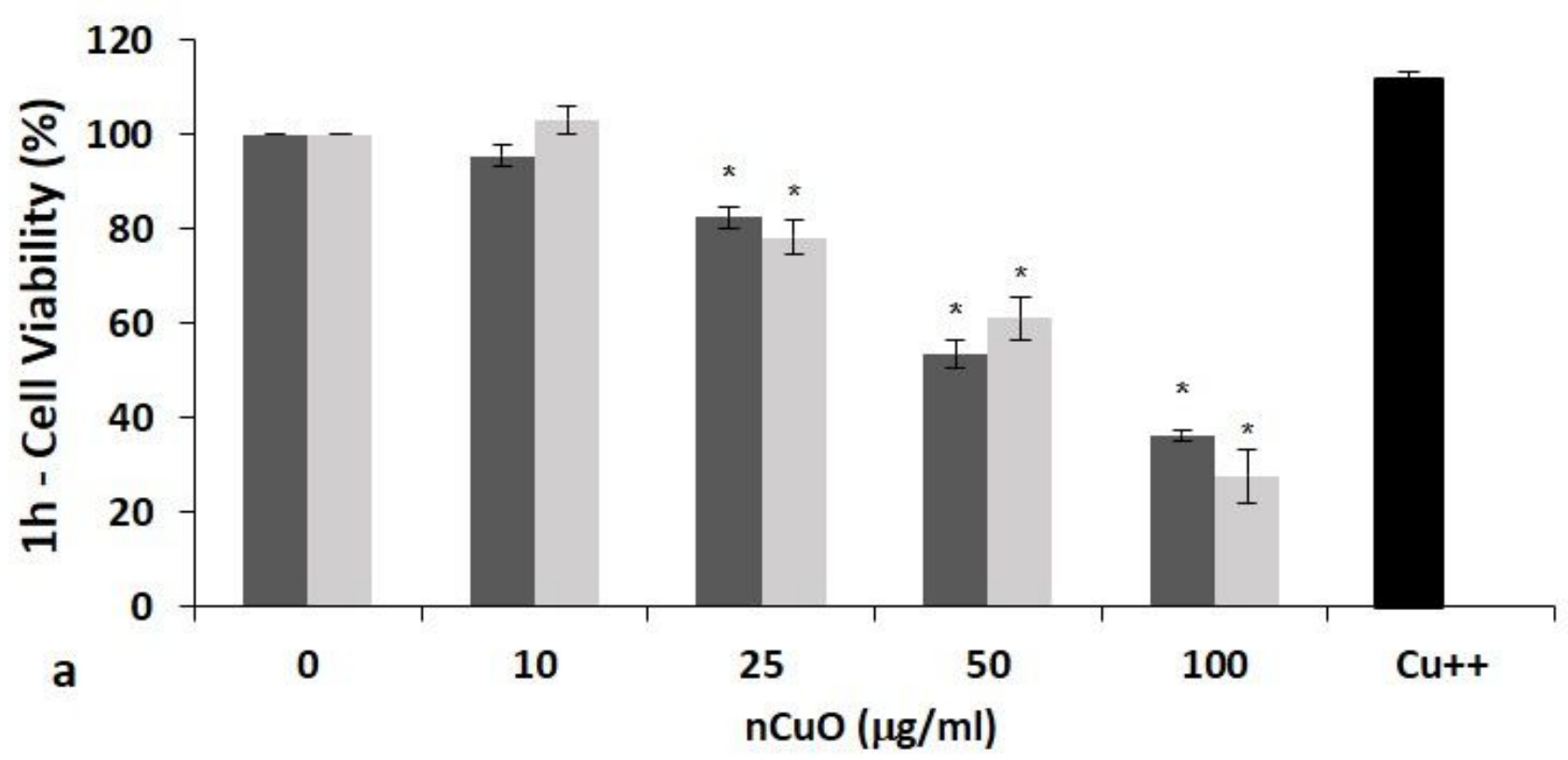

$\square \mathrm{cCuO} \quad \mathrm{sCuO}$

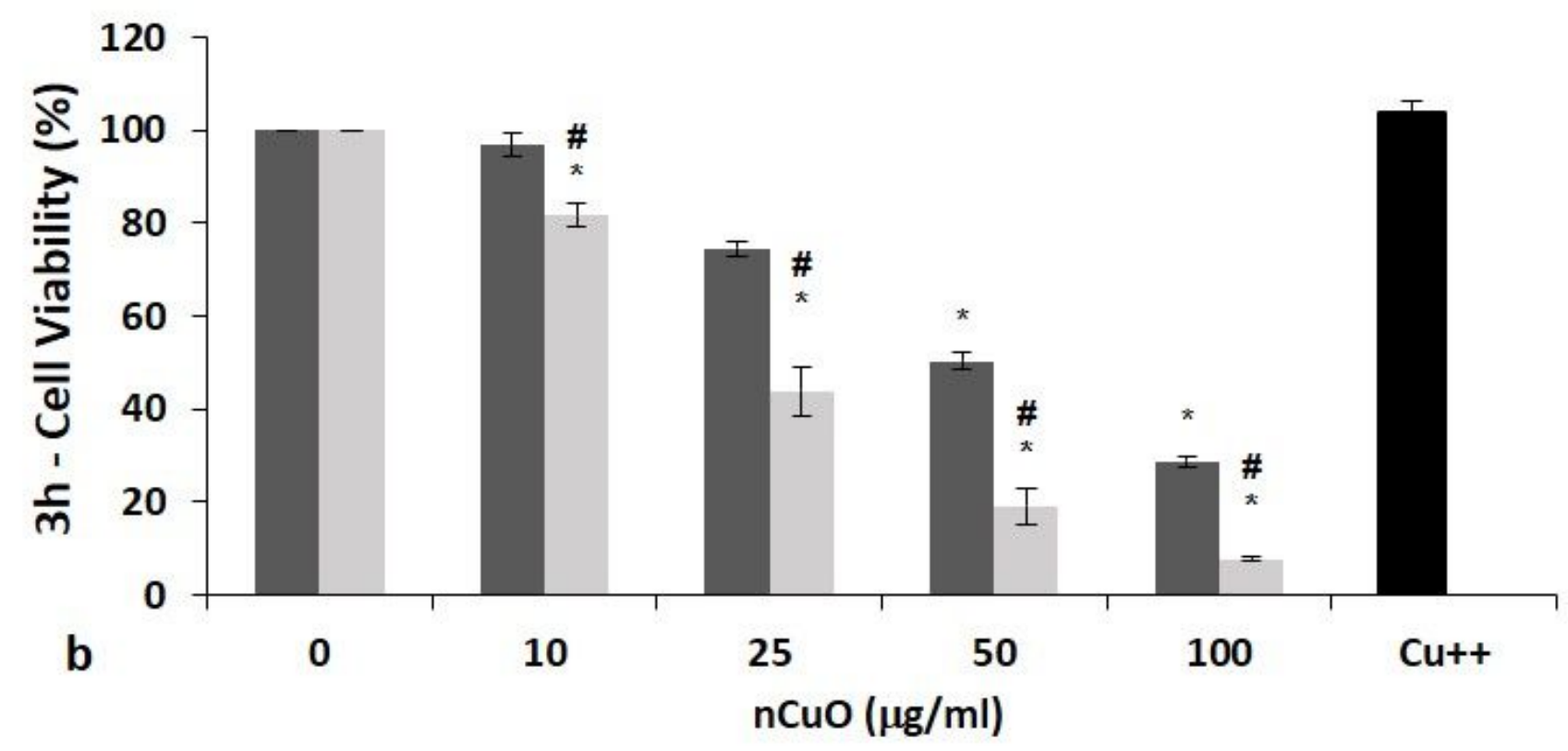

Figure 3

Cell viability results by MTT assay.

A549 cells were exposed to $\mathrm{cCuO}$ and sCuO for $1 \mathrm{~h}$ (a) and $3 \mathrm{~h}$ (b). Dark grey bars $=c C u O$; light grey bars $=$ sCuO; black bar $=80 \mathrm{mg} / \mathrm{ml} \mathrm{Cu}{ }^{++}$(from $\mathrm{CuSO}_{4} \cdot 5 \mathrm{H}_{2} \mathrm{O}$ ). * Significantly different from control (ANOVA + Fisher LSD Method, $p<0.05$ ). 

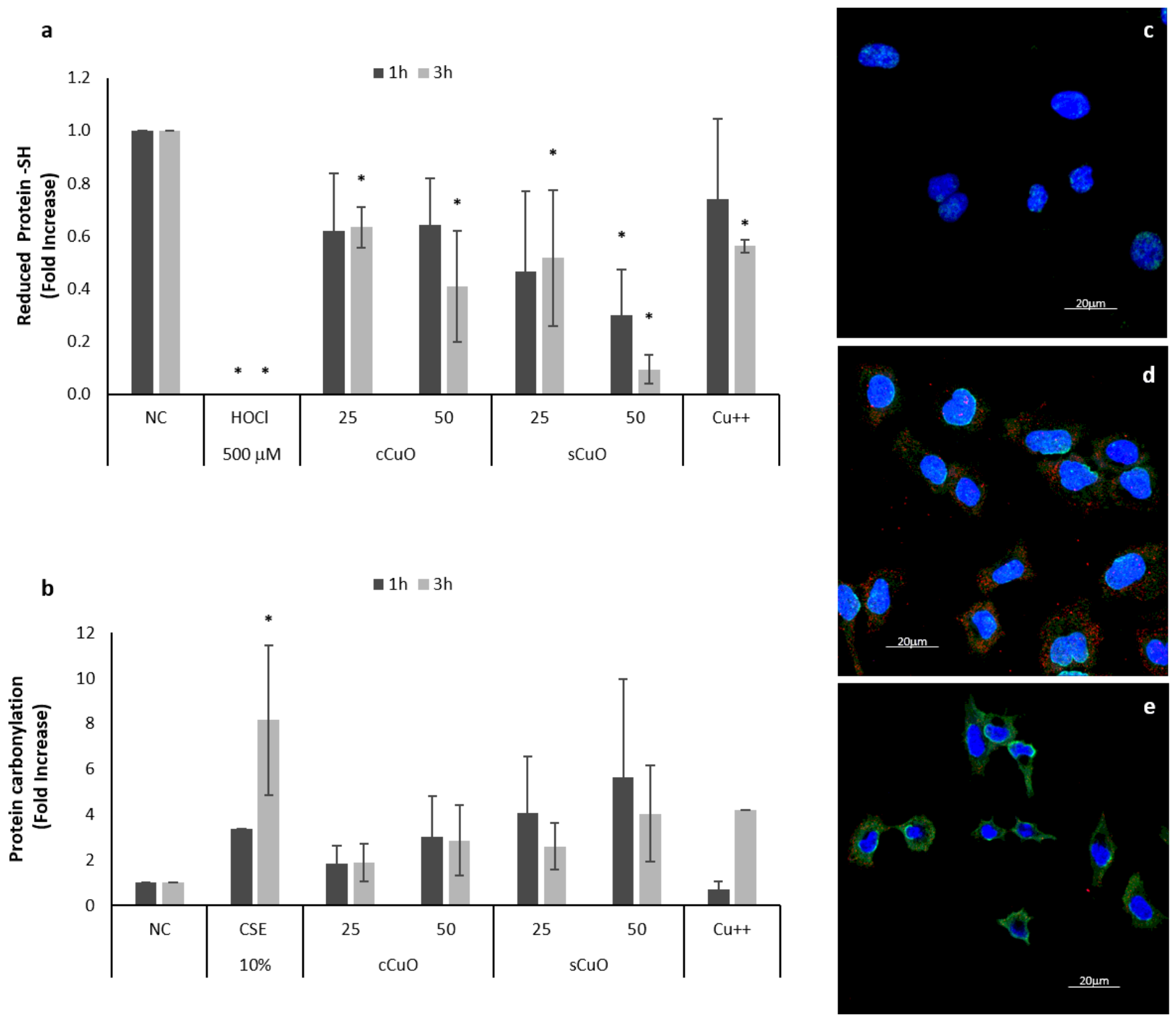

\section{Figure 4}

Short-term oxidative stress markers in A549.

Histograms $(a, b)$ show the results obtained by immunoblotting after the exposure of cells to cCuO and sCuO for $1 \mathrm{~h}$ (dark grey bars) and $3 \mathrm{~h}$ (light grey bars) about the quantification of a) Reduced protein thiols after exposure; b) Protein carbonylation (PCO). NC) Negative Control (unexposed cells); $\mathrm{HOCl}=500$ $\mathrm{mM}$ sodium hypochlorite; $\mathrm{CSE}=10 \%$ condensate smoke extract; $\mathrm{Cu}^{++}=80 \mathrm{mg} / \mathrm{m} / \mathrm{copper}$ from $\mathrm{CuSO}_{4} \cdot 5 \mathrm{H}_{2} \mathrm{O}$.

The pictures $(c, d, e)$ show the immunocytochemical detection of protein carbonyls by confocal laser scanning microscopy (CLSM) after 3 hours of exposure. Nuclei are stained by Hoechst (blue spots); CuO 
NPs are mapped by reflection mode (red spots); protein carbonyls (green spots, AlexaFluor488).

*Significantly different from control (ANOVA + Fischer LSD Method, $p<0,05$ ).

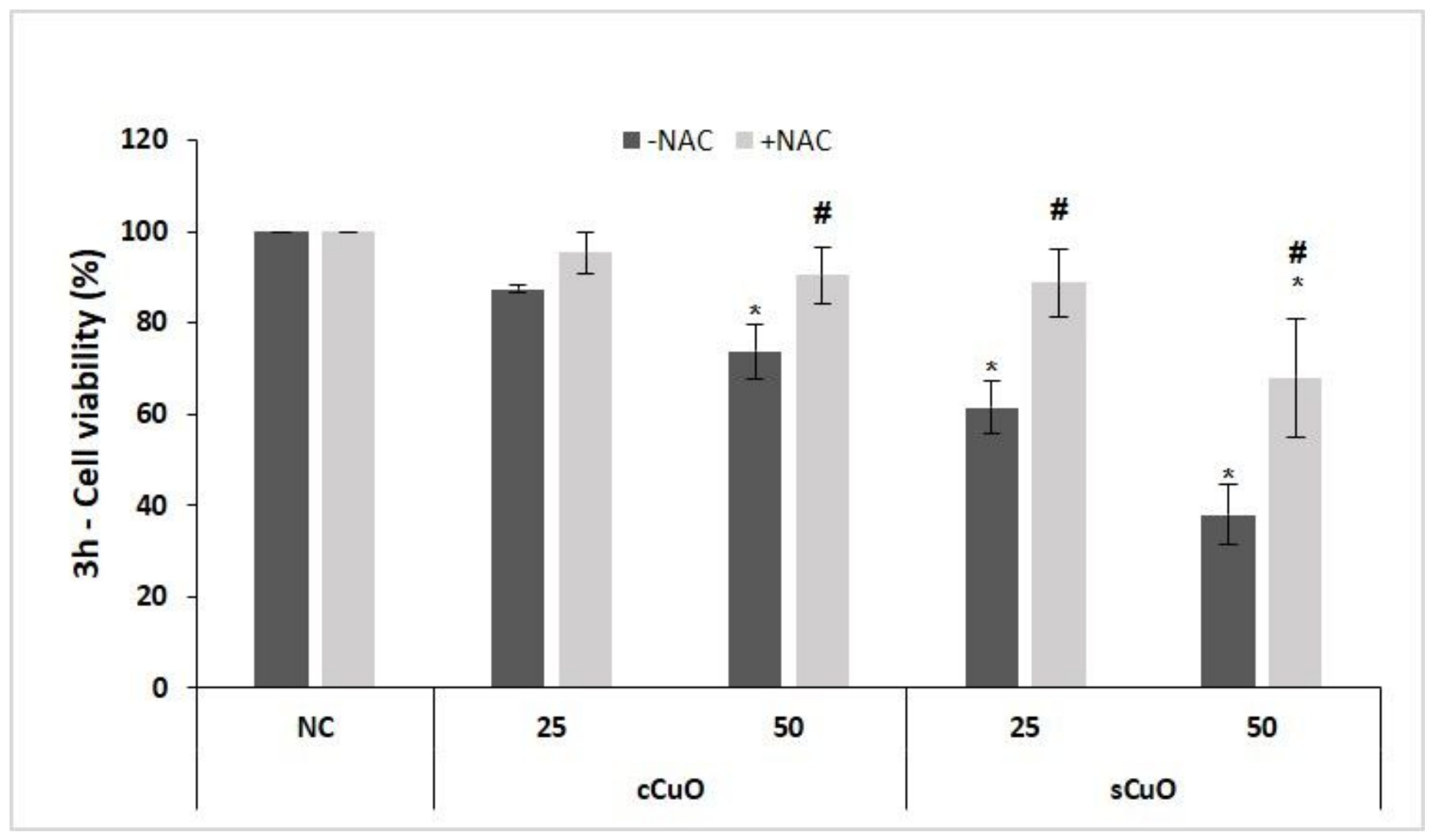

Figure 5

Cell viability results by MTT assay of A549 co-incubated with a ROS scavenger.

Cells were exposed to copper oxide nanoparticles for $3 \mathrm{~h}$ in presence of $10 \mathrm{mMNAC}(+N A C$, light grey bars) or without (-NAC, dark grey bars). *Significantly different from the negative control (NC); \# Significantly different from the correspondent experimental group without NAC (ANOVA+ Fischer LSD test; $p<0,05)$. 


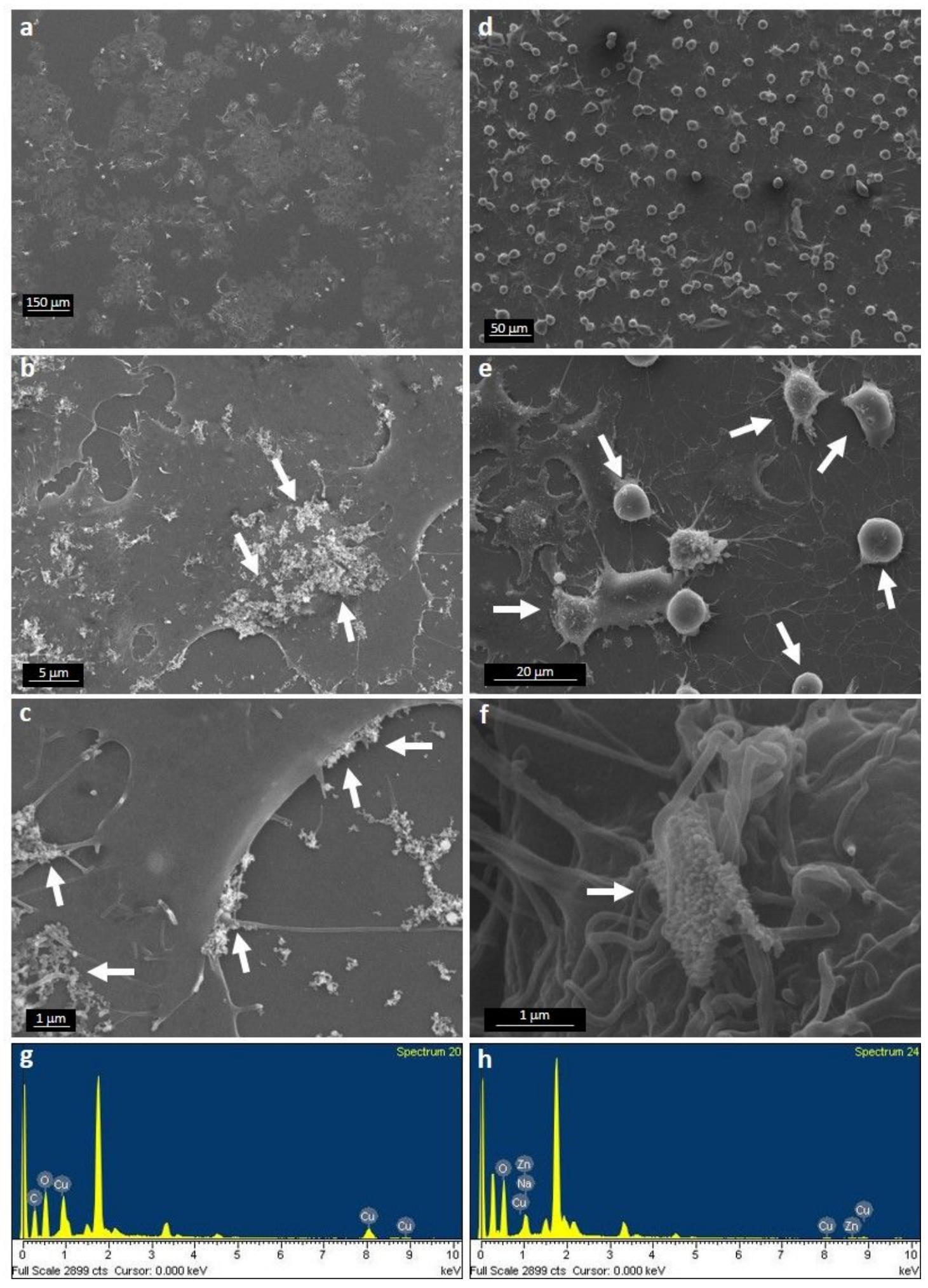

\section{Figure 6}

SEM images of A549 exposed to CuO NPS.

a) unexposed cells - in the middle a mitotic cell is visible (white arrow); $b, c)$ cells exposed to cCuO at 25 and $50 \mathrm{mg} / \mathrm{ml}$ for $3 \mathrm{~h}$-aggregates of nanoparticle are visible on the cell surface (white arrows); $d$, e) cells exposed to sCuO at 25 and $50 \mathrm{mg} / \mathrm{ml}$ for $3 \mathrm{~h}$-numerous mitotic/apoptotic cells (white arrows) are 
appreciable together with few small NP aggregates on the cell surface; f) detail of sCuO NPS agglomerates on cell surface; $g, h$ ) EDX spectra of the corresponding area, showing the Cu characteristic peaks for both cCuO and sCuO NPs $50 \mathrm{mg} / \mathrm{ml}$.

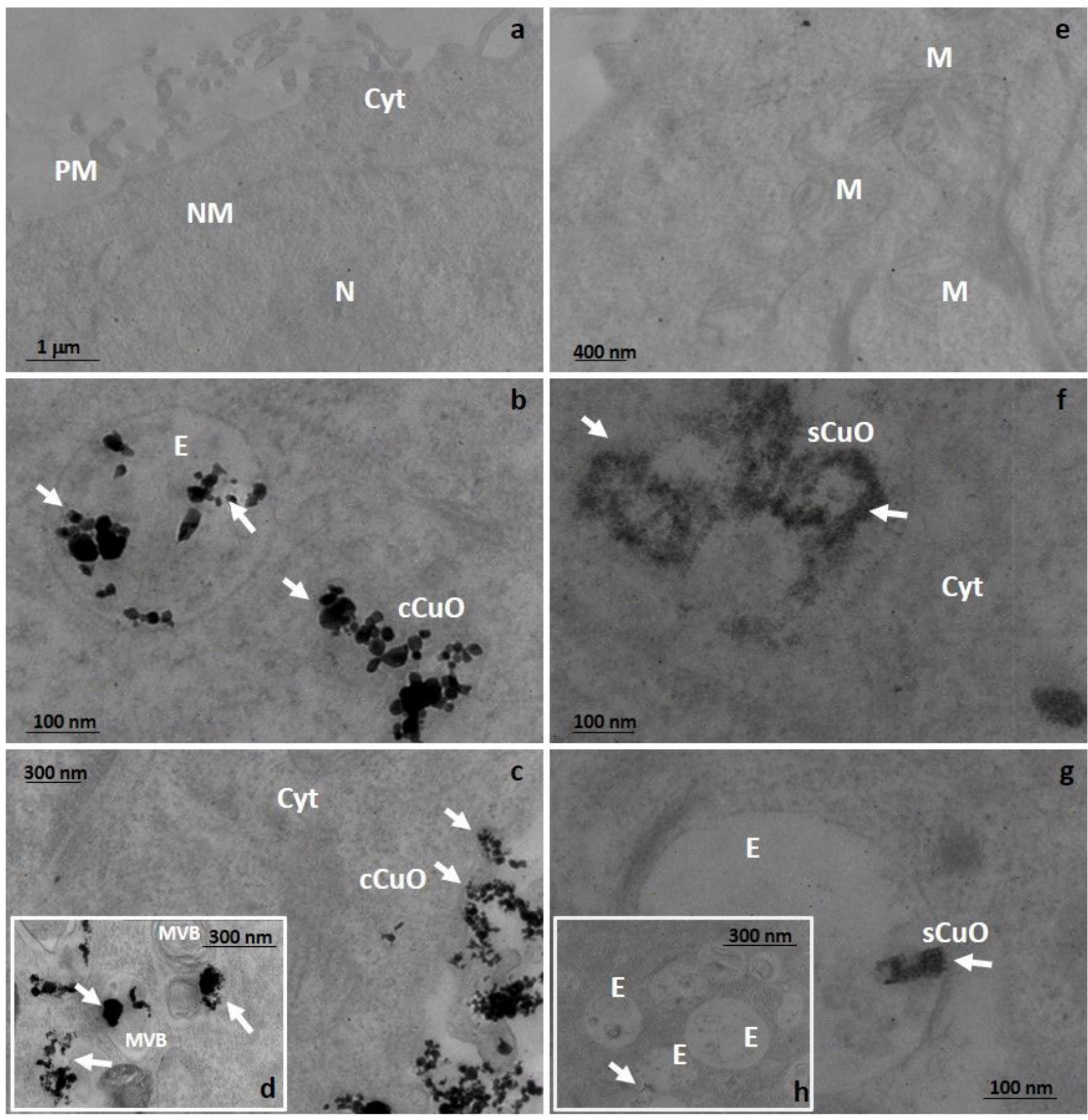

Figure 7 
TEM images of $A 549$ exposed to CuO NPS.

a, e) Unexposed cells with intact plasma membrane (PM) and organelles like mitochondria (M). b) Commercial CuO NPs $(50 \mathrm{mg} / \mathrm{ml}, 1 \mathrm{~h})$ accumulating in vesicles, likely endosomes (E); $c, d)$ detail of cCuO entering cells through the endocytic pathway at 3 h post-exposure and accumulating in MVBs (d); f) Sonochemical CuO $(50 \mathrm{mg} / \mathrm{ml}, 1 \mathrm{~h})$ already internalised at $1 \mathrm{~h}$ post-exposure and affecting cell integrity; $\mathrm{g})$ small aggregates of tiny sCuO NPs at 3 h post-exosure found in vesicles mostly of the time interacting with internal membranes (h). The white arrows indicate the presence of CuO NPs.

\section{Figure 8}

Cytochemistry of intracellular $\mathrm{Cu}^{++}$by Rhodanine staining in A549 exposed to CuO NPs.

a) negative control (unexposed cells); b) Positive control (10 mg/ml cCuO-BSA -exposed cells, 24h) with red spots testifying for the intracellular release of $\mathrm{Cu}^{++}$; c) $\mathrm{Cu}^{++}$-exposed cells (from $\mathrm{CuSO}_{4} \cdot 5 \mathrm{H}_{2} \mathrm{O}$ ); d, e) 25

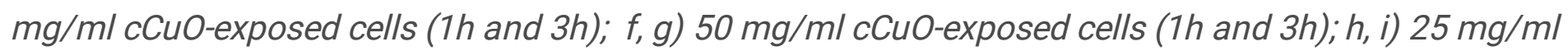

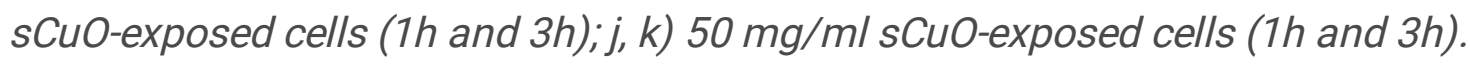



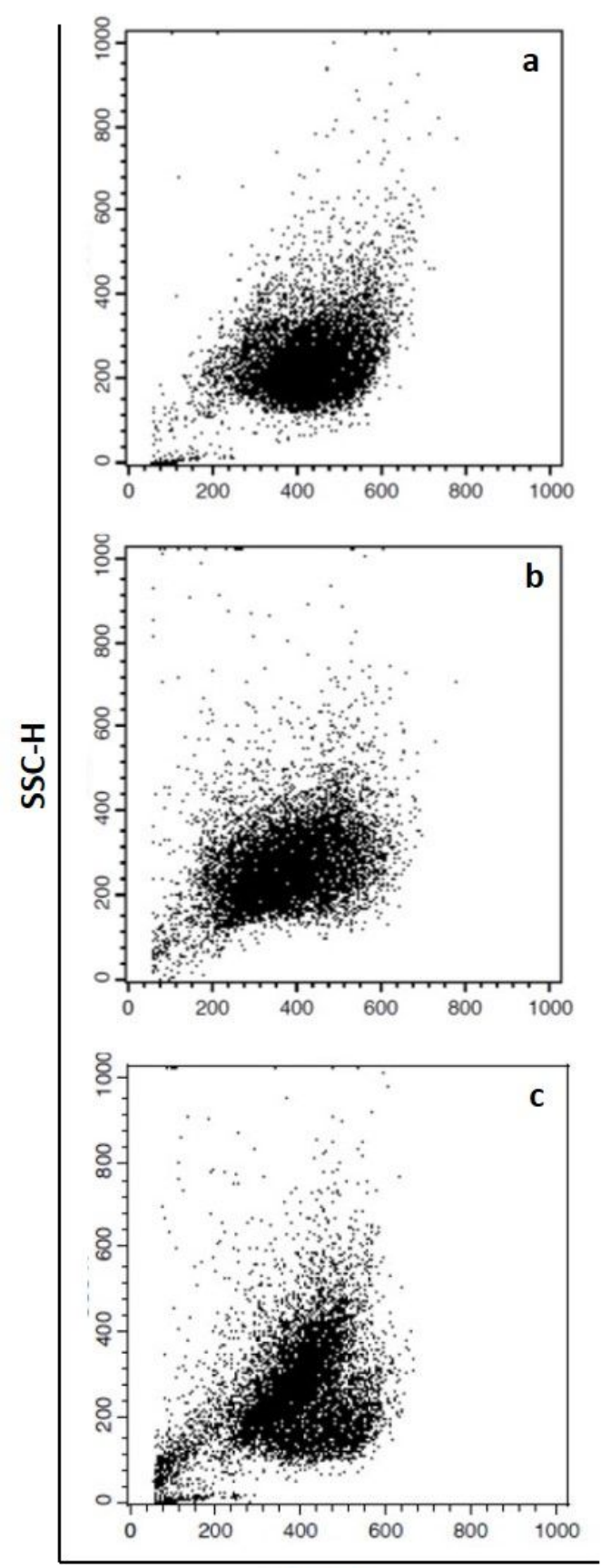

FSC-H
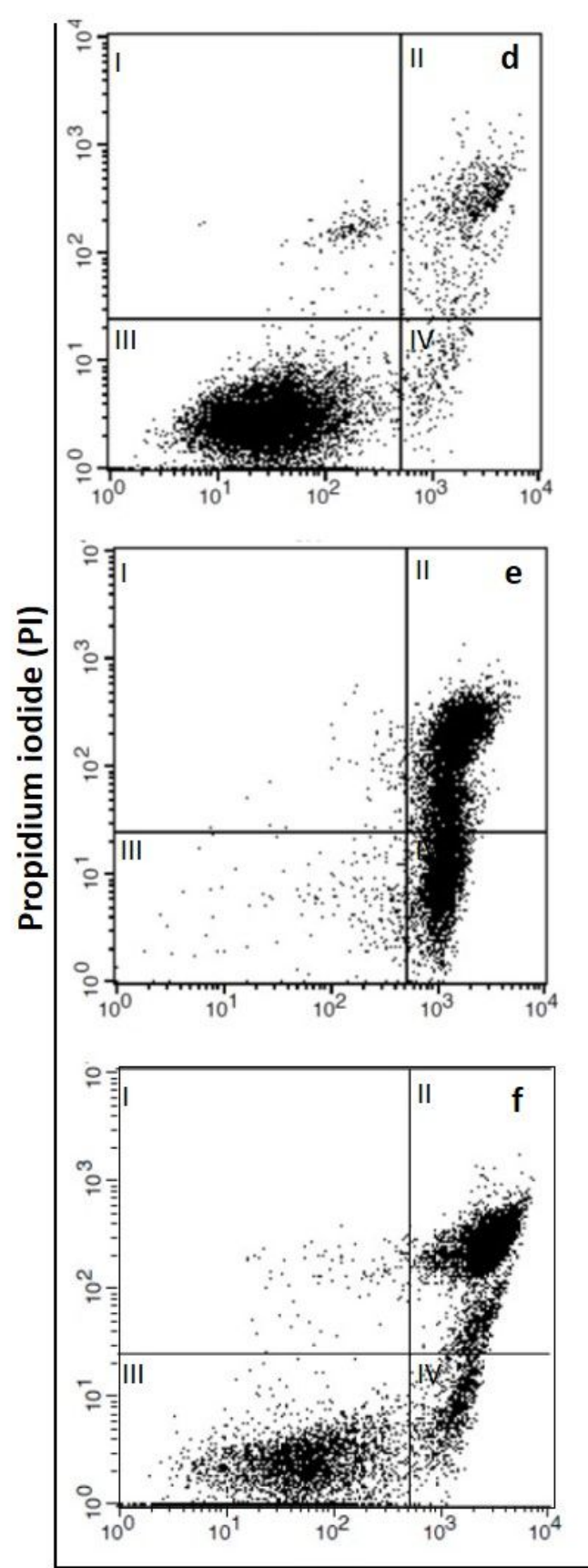

Annexin-V
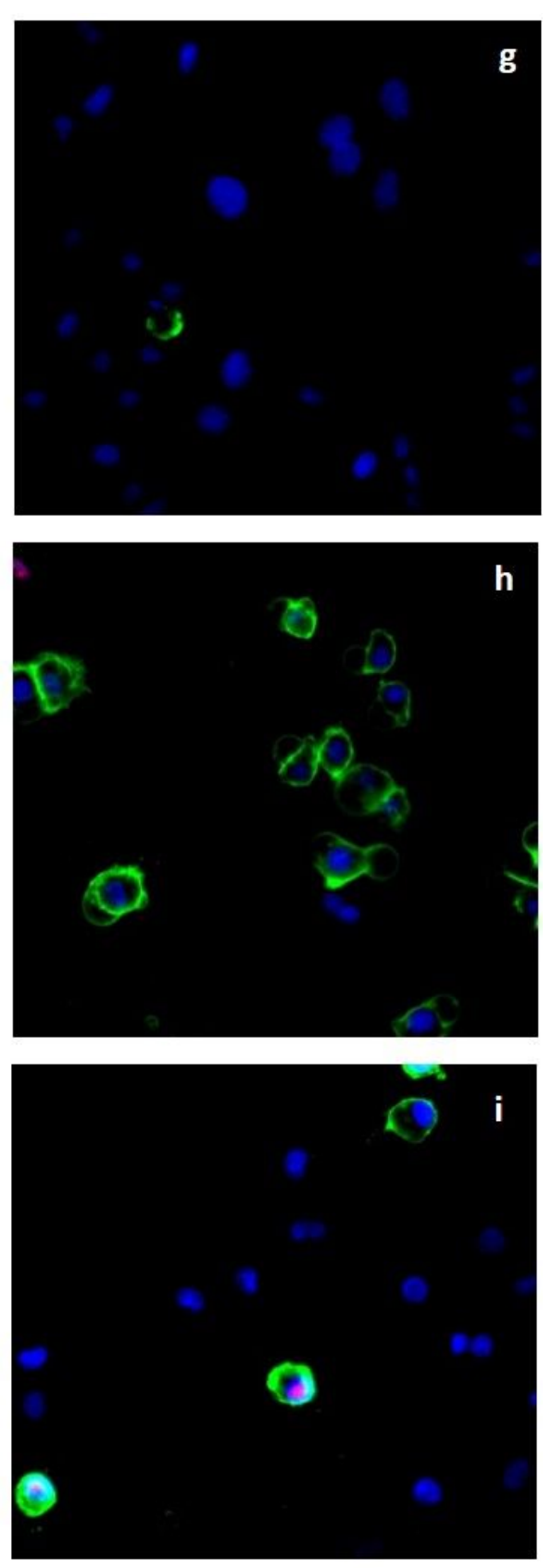

\section{Figure 9}

Short-term apoptosis detection in A549.

a-f) Representative flow cytometry plots of $A 549$ stained for apoptosis with Annexin V-FITC/PI. a-C) forward scattering (FSC-H) versus side scattering (SSC-H); d-f) contour diagrams of FITC-Annexin V/PI, log scale; The lower left quadrant of each central panel (III) shows the viable cells, which exclude PI and are negative for FITC-Annexin $V$ binding. The upper right quadrants contain the nonviable, necrotic cells, positive for both FITC-Annexin $V$ binding and for PI uptake (II). The lower right quadrants represent the apoptotic cells, FITC-Annexin V positive and PI negative demonstrating loss of cytoplasmic membrane integrity (IV). g-i) representative pictures acquired by CLSM after A549 Annexin V-FITC/PI/Hoechst 
staining. Viable cells are stained with Hoechst (b/ue), apoptotic cells show either double (blu/green) or triple (blu/red/green) staining.

$a, d, g)$ Unexposed cells; $b, e, h) 10 \mathrm{mM} \mathrm{H}_{2} \mathrm{O}_{2}$-exposed cells; c, f, i) $50 \mathrm{mg} / \mathrm{ml} \mathrm{sCuO}$-exposed cells.

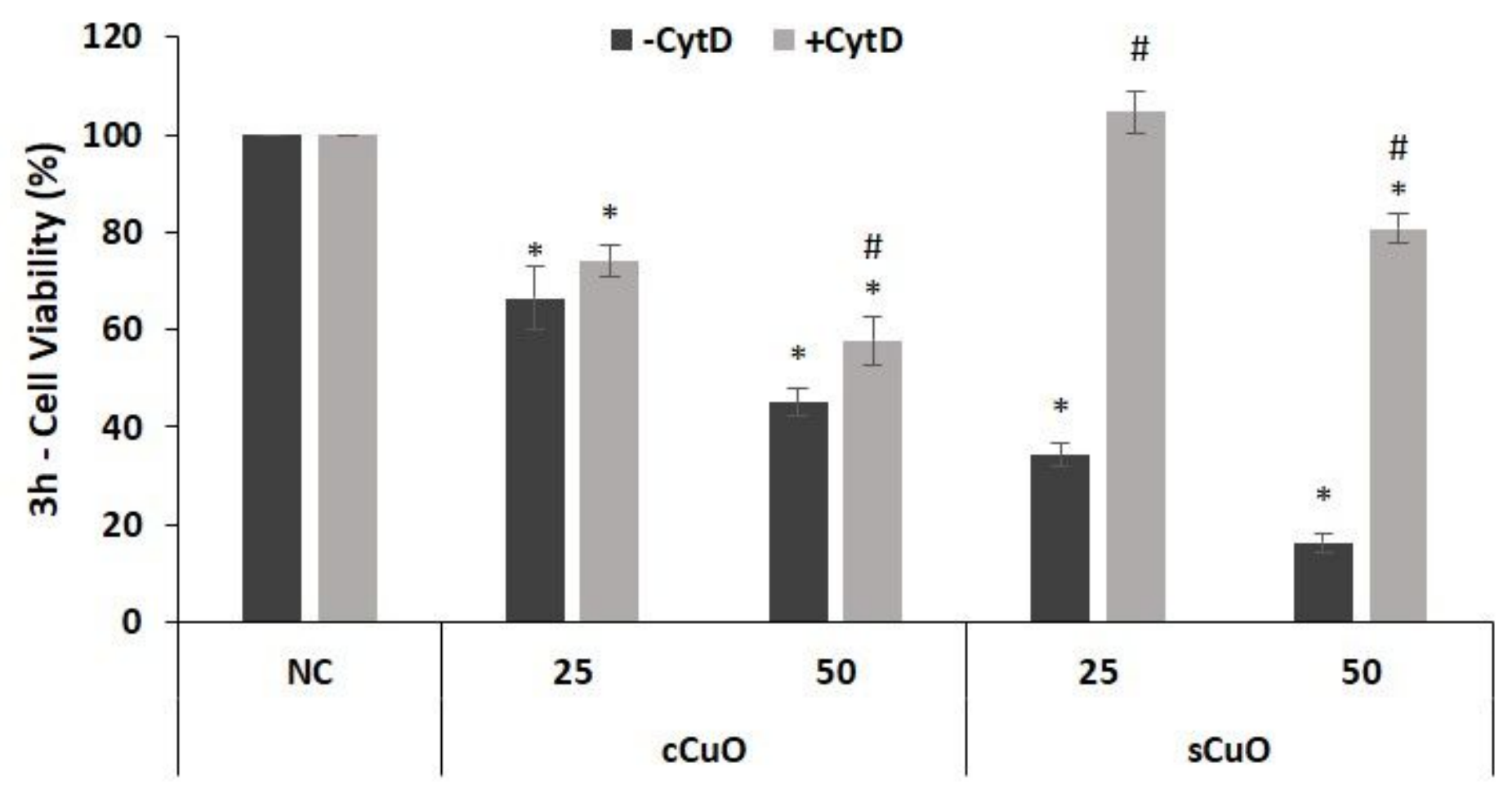

Figure 10

Cell viability results by MTT assay of A549 pre-incubated with an endocytosis inhibitor.

Cells were exposed to copper oxide nanoparticles for $3 \mathrm{~h}$ after pre-incubation with $4 \mathrm{mM}$ Cytocalasin $D$ (+CytD, light grey bars) or without pre-incubation (-CytD, dark grey bars). *Significantly different from the negative control (NC); \# Significantly different from the correspondent experimental without inhibitor (ANOVA + Fisher $L S D, p<0.05)$. 


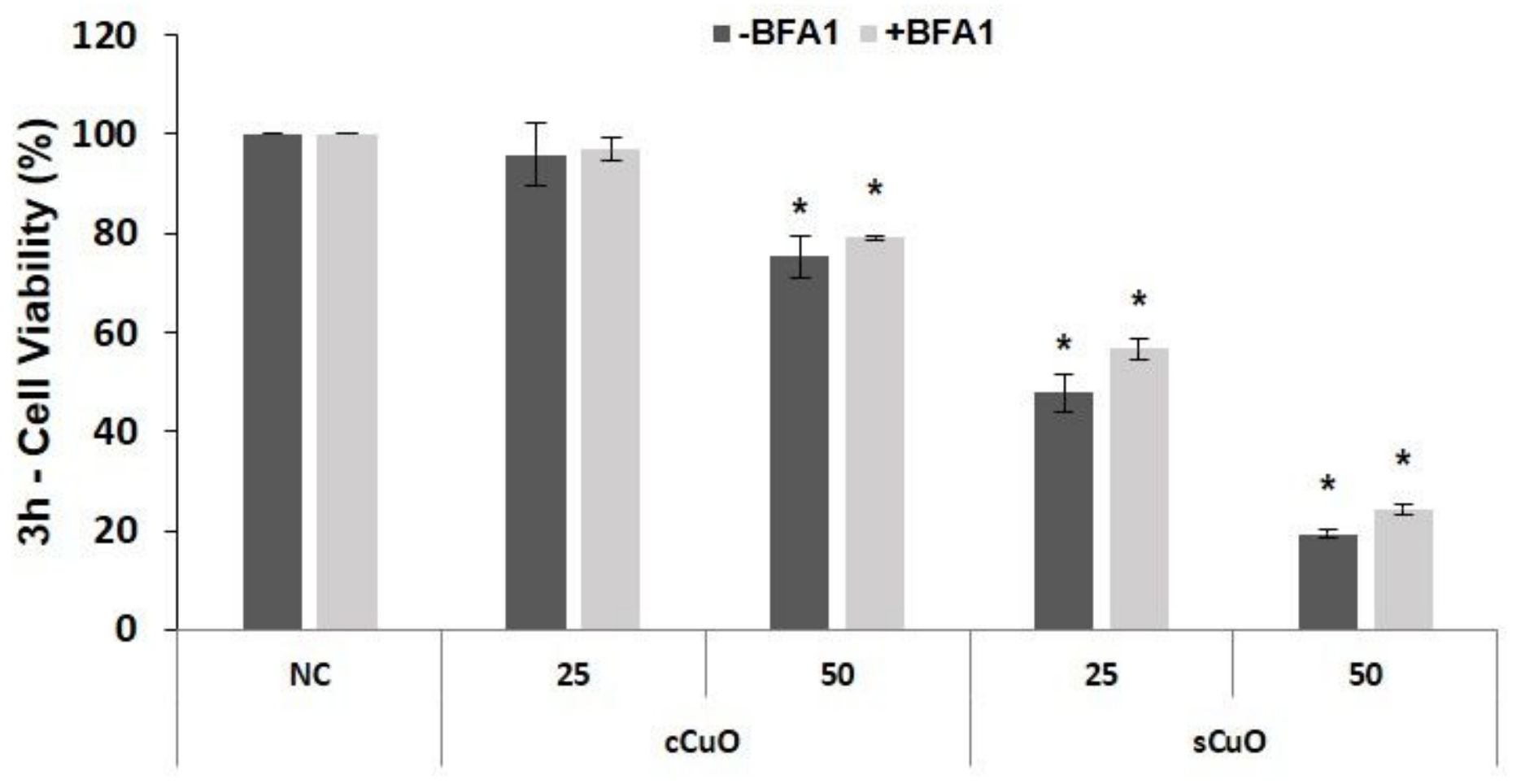

Figure 11

Cell viability results by MTT assay of A549 pre-incubated with a proton-pump inhibitor.

Cells were exposed to copper oxide nanoparticles for $3 \mathrm{~h}$ after pre-incubation with Bafilomycin A1 (+BFA1, light grey bars) or without pre-incubation (-BFA1, dark grey bars). *Significantly different from the negative control (NC). \#Significantly different from correspondent experimental group without inhibitor (ANOVA + Fisher LSD, $p<0.05)$.

\section{Supplementary Files}

This is a list of supplementary files associated with this preprint. Click to download.

- Moschinietal.2021Additionalfile1.docx

- Moschinietal.2021Additionalfile3.docx

- Moschinietal.2021Additionalfile2.docx 